\title{
Tenascin-C Promotes Neurite Outgrowth of Embryonic Hippocampal Neurons through the Alternatively Spliced Fibronectin Type III BD Domains via Activation of the Cell Adhesion Molecule F3/Contactin
}

\author{
Franck Rigato, ${ }^{1}$ Jeremy Garwood, ${ }^{1}$ Valérie Calco, ${ }^{1}$ Nicolas Heck, ${ }^{1}$ Catherine Faivre-Sarrailh, ${ }^{2}$ and \\ Andreas Faissner ${ }^{3}$ \\ 1 Laboratoire de Neurobiologie du Développement et de la Régénération, Centre National de la Recherche Scientifique, \\ Formation der Recherche en Évolution 2373, F-67084 Strasbourg, France, 2Laboratoire de Génétique et de Physiologie \\ de Développement, Centre National de la Recherche Scientifique, Unité Mixte de Recherche 6545, F-13288 Marseille, \\ France, and ${ }^{3}$ Department of Cell Morphology and Molecular Neurobiology, Ruhr-University, 44801 Bochum, Germany
}

Tenascin- $C$ is a multimodular glycoprotein that possesses neurite outgrowth-stimulating properties, and one functional site has been localized to the alternatively spliced fibronectin type III domain D. To identify the neuronal receptor that mediates this effect, neighboring pairs of fibronectin type III domains were expressed as hybrid proteins fused to the Fc fragment of human immunoglobulin. These IgFc fusions were tested for neurite outgrowth-promoting properties on embryonic day 18 rat hippocampal neurons, and both the combinations BD and D6 were shown to promote the elongation of the longest process, the prospective axon. Antibodies to the cell adhesion molecule F3/contactin of the Ig superfamily blocked the BDbut not the D6-dependent effect. Biochemical studies using
F3/contactin-IgFc chimeric proteins confirmed that the adhesion molecule selectively reacts with the combination BD but not with other pairs of fibronectin type III repeats of tenascin-C. The alternatively spliced BD cassettes are prominently expressed in the developing hippocampus, as shown by reverse transcription PCR, and colocalize with F3 expression during perinatal periods when axon growth and the establishment of hippocampal connections take place. We conclude that F3/ contactin regulates axon growth of hippocampal neurons in response to tenascin-C.

Key words: tenascin-C; F3/contactin/F11; extracellular matrix; cell adhesion molecules; neurite outgrowth; hippocampus development
The extracellular matrix (ECM) regulates developmental mechanisms in the CNS. Neurite outgrowth and guidance depend on various molecules with supportive or inhibitory properties for axon growth (Tessier-Lavigne and Goodman, 1996; Mueller, 1999). Tenascin-C (TN-C) is a prominent component of the neural ECM, which plays important roles during development by affecting neurite outgrowth and guidance (Joester and Faissner, 2001). TN-C was originally visualized by electron microscopy as a hexameric multimer termed hexabrachion. Monomers display a modular structure with an $\mathrm{N}$ terminus called the TN assembly domain, followed by 14.5 epidermal growth factor-like repeats and a series of fibronectin type III (FNIII) domains, and terminate with a $\mathrm{C}$ terminus that presents homologies with fibrinogens $\beta$ and $\gamma$ (Saga et al., 1991; Weller et al., 1991). Spliced variants of

Received March 22, 2002; revised May 7, 2002; accepted May 9, 2002.

This work was supported by Centre National de la Recherche Scientifique (CNRS), German Research Council Deutsche Forschungsgemeinschaft Grant SFB 317/A2 (A.F.), and Association pour la Recherche contre le Cancer (ARC) Grant 583032. F.R. was a recipient of the Région Alsace Graduate Training Stipend 788-98 and ARC Grant ML/MLD/CM-P00/4 and was supported by the International Graduate School for Neuroscience (Ruhr-University, Bochum, Germany); N.H. was a recipient of Ministère National de l'Education, de la Recherche et de la Technologie Graduate Training Stipend 99090; and J.G. was awarded a Poste rouge from the CNRS during part of this work. The advice of Dr. Monique Jouet (London, UK) during the initial stages of the construction of chimeric proteins is gratefully acknowledged.

Correspondence should be addressed to Dr. Andreas Faissner, Ruhr-University, Department of Cell Morphology and Molecular Neurobiology, Universitätstrasse 150, 44801 Bochum, Germany. E-mail: andreas.faissner@ruhr-uni-bochum.de. Copyright (C) 2002 Society for Neuroscience $0270-6474 / 02 / 226596-14 \$ 15.00 / 0$
TN-C display varying numbers of FNIII domains, which result from the independent insertion of up to six additional FNIII domains between the FNIII modules 5 and 6 of the smallest variant (Dörries and Schachner, 1994). So far, 27 variants have been identified in mouse brain (Joester and Faissner, 1999). Moreover, FNIII repeats in TN-C variants are expressed differentially during development (Joester and Faissner, 1999). Taken together, these observations suggest a large structural and functional diversity of TN-C isoforms. This raises the question of whether the combinations of FNIII cassettes can differentially modulate the capacity of TN-C to exert inhibitory, stimulatory, nonadhesive, or adhesive effects on neural cells (Bartsch, 1996). Previous experiments reported the involvement of TN-C in the promotion and polarization of hippocampal neurons. Fusion proteins expressed in bacteria provided evidence that FNIII domains BD and D6 stimulate neurite extension, whereas distinct sites are involved in neurite deflection and cell binding (Dörries et al., 1996; Götz et al., 1996; Meiners and Geller, 1997; Meiners et al., 1999b). Along these lines, a role for FNIII domain C in axon guidance has been attributed (Meiners et al., 1999a), and a peptide containing eight amino acids of FNIII repeat D, which is well conserved in different species, has been identified as crucial for neurite outgrowth promotion by TN-C (Meiners et al., 2001).

Several putative TN-C receptors have been presented, which include integrins, cell adhesion molecules, and proteoglycans. Integrins $\alpha \mathrm{v} \beta 3$ and $\alpha 9 \beta 1$ interact with FNIII domain 3 (Yokosaki et al., 1998), and integrin $\alpha 8 \beta 1$ binds fragments including the 


\begin{tabular}{|c|c|c|c|}
\hline Recombinant protein & $\begin{array}{l}\text { Restriction } \\
\text { site }\end{array}$ & $\begin{array}{l}\text { Orientation } \\
5^{\prime} \rightarrow 3^{\prime}\end{array}$ & Oligonucleotide primers \\
\hline \multirow[t]{2}{*}{$\mathrm{TNfnA}_{1} \mathrm{~A}_{2}-\mathrm{Fc}$} & Kpn I & Sense & CGG GGT ACC GAA GAA GTG CCT TCC CTG C \\
\hline & $X b a \mathrm{I}$ & Antisense & C TAG TCT AGA TGT CAA GAC CTC AAC AGA G \\
\hline \multirow[t]{2}{*}{$\mathrm{TNfnA}_{1} \mathrm{D}-\mathrm{Fc}$} & Kpn I & Sense & CGG GGT ACC GAA GAA GTG CCT TCC CTG C \\
\hline & $X b a \mathrm{I}$ & Antisense & C TAG TCT AGA TGT TGT TGC TAT GGC ACT G \\
\hline \multirow[t]{2}{*}{ TNfnBD-Fc } & KpnI & Sense & CGG GGT ACC GCC AGA GAA CCT GAA ATT GG \\
\hline & $X b a \mathrm{I}$ & Antisense & C TAG TCT AGA TGT TGT TGC TAT GGC ACT G \\
\hline \multirow[t]{2}{*}{ TNfnCD-Fc } & KpnI & Sense & CGG GGT ACC GAG GCC TTG CCC CTT CTG G \\
\hline & $X b a \mathrm{I}$ & Antisense & C TAG TCT AGA TGT TGT TGC TAT GGC ACT G \\
\hline \multirow[t]{2}{*}{ TNfnD6-Fc } & $K p n \mathrm{I}$ & Sense & CGG GGT ACC GAA GCT GAA CCG GAA GTT G \\
\hline & $X b a \mathrm{I}$ & Antisense & C TAG TCT AGA TGT GAT TAG AGT CCC CGA G \\
\hline \multirow[t]{2}{*}{ TNfn78-Fc } & Kpn I & Sense & CGG GGT ACC GCT CTG GAT GGT CCA TCT G \\
\hline & $X b a \mathrm{I}$ & Antisense & C TAG TCT AGA TGT TGT GAA GAT GGT TTG G \\
\hline pIgPlus SEQ 5' & & Sense & CGA CTC ACT ATA GGG AGA CCC \\
\hline pIgPlus SEQ 3' & & Antisense & CAT GTG TGA GGT TTG TCA CAA G \\
\hline
\end{tabular}

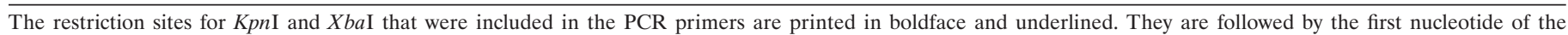
corresponding fibronectin type III repeat chosen for amplification, as indicated.

FNIII cassettes 6-8 (Varnum-Finney et al., 1995; Denda et al., 1998). Among the Ig cell adhesion molecules (IgCAMs), contactin/F11 has been described as a ligand of the unspliced chick TN-C variant and TN-R/restrictin (Norenberg et al., 1995; Weber et al., 1996). Transient axonal glycoprotein-1 (TAG-1)/axonin-1 has also been proposed as a potential receptor of TN-C (Milev et al., 1996). Finally, the proteoglycans phosphacan (Milev et al., 1997), neurocan (Milev et al., 1997; Rauch et al., 1997), and syndecan (Jalkanen et al., 1992) have been identified as ligands of TN-C. Although various TN-C receptors have been characterized on the basis of biochemical binding studies, none of them so far has been implicated in regulating axon outgrowth in response to TN-C.

To further understand the relationship between the structure of TN-C isoforms and their roles in neurite outgrowth, we have focused our efforts on the identification of neuronal receptors of the FNIII domains that incorporate neurite outgrowthpromoting effects. Using recombinant $\mathrm{IgFc}$ fusion proteins, we demonstrate here that the FNIII BD domains of TN-C are selectively recognized by $\mathrm{F} 3 /$ contactin and that this interaction is required for enhanced neurite outgrowth from embryonic day 18 (E18) hippocampal neurons.

\section{MATERIALS AND METHODS}

Antibodies. Mouse anti- $\alpha$-tubulin and mouse anti- $\beta$ III-tubulin monoclonal antibodies and goat HRP-conjugated anti-rat, goat anti-mouse, and goat anti-rabbit secondary antibodies were purchased from Sigma (Deisenhofen, Germany). Goat Alexa Fluor-488 nm (Molecular Probes Europe) and Cy3 (Jackson ImmunoResearch, West Grove, PA)-conjugated secondary antibodies were used for immunocytochemistry. Nonconjugated and HRP-conjugated goat anti-human Fc IgG antibodies were purchased from Sigma.

Monoclonal antibodies against TN-C were purified and concentrated from rat hybridomas growing in serum-free medium (Faissner and Kruse, 1990; Husmann et al., 1992). These antibodies are directed against TNegf (J1/tn3, clone 630), FNIII repeat $\mathrm{A}_{2}$ (J1/tn1, clone 576) and FNIII module D (J1/tn2, clone 578). Polyclonal antibodies to TN-C (Kaf14) have been described previously (Faissner and Kruse, 1990).

Polyclonal antisera specific for F3/contactin (pAbF3) directed against amino acids 37-50 (peptide KGFGPIFEEQPINT) were raised in rabbits using standard procedures (Koch et al., 1997). For functional tests, $\mathrm{pAbF} 3$ was purified by chromatography on protein A-Sepharose CL-4B (Amersham Biosciences, Braunschweig, Germany) using a standard protocol, dialyzed against PBS (in mM: $150 \mathrm{NaCl}, 10 \mathrm{KH}_{2} \mathrm{PO}_{4}$, and 10
$\mathrm{Na}_{2} \mathrm{HPO}_{4}-2 \mathrm{H}_{2} \mathrm{O}, \mathrm{pH}$ 7.4), and filtered in sterile conditions (pore diameter, $0.22 \mu \mathrm{m}$; Millipore Europe). A monoclonal antibody from mouse made against chick contactin/F11 (mAbF3, clone 27-6-221; Brummendorf et al., 1993), which cross-reacts with mouse F3, was kindly provided by Dr. F. G. Rathjen (Department of Developmental Neurobiology, Max-Delbrück-Center for Molecular Medicine, Berlin, Germany).

ECM proteins. Laminin-1 (LN-1) isolated from Engelbreth-HolmSwarm mouse sarcoma cells was purchased from Boehringer Mannheim (Mannheim, Germany). TN-C from postnatal day 7 (P7)-P14 mouse brains was obtained by immunoaffinity chromatography, as described previously (Faissner and Kruse, 1990).

Animals. For the preparation of cell cultures, the histochemistry, and the reverse transcription (RT)-PCR experiments from embryonic and postnatal brains, Wistar rats were used. Fauve de Bourgogne rabbits were used for immunization and pAbF3 antibody production. All animals were kept at local facilities (Centre de Neurochimie, Strasbourg, France).

Fc recombinant proteins: construction, expression, production, and characterization. The cDNA of TN-C has been described previously (Weller et al., 1991). The constructs encoding the cDNA of mouse TN-C inserts were generated by PCR. Six different constructs corresponding to fibronectin type III domains were produced: $\mathrm{TNfnA}_{1} \mathrm{~A}_{2}, \mathrm{TNfnA}_{1} \mathrm{D}$, TNfnBD, TNfnCD, TNfnD6, and TNfn7,8 (Fig. 1A). Cloning was performed into the pIgPlus expression vector (Invitrogen), which contains an upstream CD33 signal peptide sequence necessary for the secretion of chimeras and a human IgG Fc fragment sequence downstream. PCRs were done in a total volume of $25 \mu \mathrm{l}$ of water supplied with a $0.25 \mathrm{~mm}$ concentration of each dNTP, $15 \mathrm{mM}\left(\mathrm{NH}_{4}\right)_{2} \mathrm{SO}_{4}, 2 \mathrm{mM} \mathrm{MgCl} \mathrm{Mg}_{2}, 60 \mathrm{~mm}$ Tris- $\mathrm{HCl}, \mathrm{pH} 8.8$, and $1 \mathrm{IU}$ of Taq polymerase (AGS) per reaction. Amplification of FNIII domains from TN-C was achieved by using $1 \mu \mathrm{l}$ of cDNA as template (Joester and Faissner, 1999) in the presence of 500 nM concentrations of the appropriate sense and antisense primers (Invitrogen) as documented in Table 1 . Cycling was performed using a thermocycler (PE-9600; Applied Biosystems, Foster City, CA) and initiated by a $3 \mathrm{~min}$ denaturation step at $94^{\circ} \mathrm{C}$, followed by 25 cycles of $1 \mathrm{~min}$ at $94^{\circ} \mathrm{C}, 1 \mathrm{~min}$ at $65^{\circ} \mathrm{C}, 2 \mathrm{~min}$ at $72^{\circ} \mathrm{C}$, and a final extension step at $72^{\circ} \mathrm{C}$ for $5 \mathrm{~min}$. The constructs were then sequenced using an ALFexpress II sequencer (Amersham Biosciences) with the pIgPlus SEQ 5' and 3' primers (Table 1) to confirm the open reading frame and the absence of mutations. For protein expression, wild type Chinese hamster ovary (CHO) cells (European Collection of Animal Cell Cultures) were transfected with the different TN-C Fc fusion protein constructs and plasmids by electroporation (Gene Pulser electroporator; Bio-Rad, Hercules, CA; conditions: $960 \mu \mathrm{F}, 250 \mathrm{~V})$ in serum-free medium and grown for $24 \mathrm{hr}$ in Ham's F-12 medium (Invitrogen) containing 10\% fetal calf serum (Invitrogen). The following day, cell cultures were treated with the selection antibiotic Geneticin (Invitrogen) at $1 \mathrm{mg} / \mathrm{ml}$ medium. Stable clones were selected by the cloning ring method, followed by limiting dilution. For large-scale production, conditioned media were collected from cultures during $10 \mathrm{~d}$ in the presence of $10 \mathrm{~mm}$ sodium butyrate to stimulate 
protein expression, and purification was realized on protein A-Sepharose columns (Amersham Biosciences, Uppsala, Sweden). Purified proteins were

dialyzed against PBS for $24 \mathrm{hr}$ at $4^{\circ} \mathrm{C}$ in a Spectra/Por membrane (molecular weight cutoff, 12,000-14,000; Spectrum Laboratories, Rancho Dominguez, CA). The chimeric proteins were further characterized by SDS-PAGE and Western blotting. The recombinant protein, called F3Fc, has been described previously (Revest et al., 1999).

Coupling of Fc chimeras to microfluorospheres and sphere aggregation assays. Conditioned medium containing Fc recombinant proteins (TNfn-Fc or F3-Fc) was incubated with yellow-green (emission at 505/ $515 \mathrm{~nm}$ ) or red (emission at $580 / 605 \mathrm{~nm}$ ) fluorescing microspheres (fluorospheres, nominal diameter $1 \mu \mathrm{m}$; Molecular Probes) previously conjugated covalently with a goat anti-human Fc IgG antibody. Fifty micrograms of anti-human Fc were incubated with $5 \times 10^{9}$ fluorospheres in $1 \mathrm{ml}$ of PBS for $16 \mathrm{hr}$ at $25^{\circ} \mathrm{C}$ under shaking. The fluorospheres were centrifuged at $2500 \times g$ for $2 \mathrm{~min}$, resuspended in PBS containing $5 \%$ (w/v) bovine serum albumin (BSA; Sigma) and $10 \mathrm{~mm} \mathrm{NaN}_{3}$, and incubated for $16 \mathrm{hr}$ at $4^{\circ} \mathrm{C}$ with several batches of conditioned medium from transfected $\mathrm{CHO}$ clones or COS-7 cells expressing TNfn-Fc and F3-Fc chimeras, respectively. After washing, fluorospheres were stored at $4^{\circ} \mathrm{C}$ in PBS, $5 \%(\mathrm{w} / \mathrm{v}) \mathrm{BSA}$, and $10 \mathrm{~mm} \mathrm{NaN}_{3}$.

Aggregation assays were performed in $20 \mu \mathrm{l}$ of PBS and 5\% BSA by mixing $1 \mu$ l of yellow and red beads derivatized with Fc chimeras. In some experiments, chimeric protein interactions were blocked by preincubation of F3-Fc-conjugated beads with pAbF3 in $100 \mu \mathrm{l} \mathrm{PBS}$ and $5 \%$ BSA for $1 \mathrm{hr}$ at $37^{\circ} \mathrm{C}$ and washing twice in PBS and $5 \% \mathrm{BSA}$. Mixtures were sonicated for $2 \mathrm{~min}$ at room temperature and incubated for $1 \mathrm{hr}$ at $37^{\circ} \mathrm{C}$ with gentle shaking. Beads were subsequently diluted 10 -fold, spread on glass slides, and mounted with Mowiol (Calbiochem). Results were observed by confocal microscopy and analyzed by counting mixed bead aggregates in 20 microscopy fields (magnification, 40×). One mixed aggregate was defined as containing at least 20 beads of each color.

Pull-down assays using Fc recombinant proteins as probes. For pull-down assays using Fc recombinant proteins, 20 total brains of Swiss OF1 mice were dissected and homogenized in $40 \mathrm{ml}$ of homogenization buffer [ 50 mM Tris- $\mathrm{HCl}$, pH 7.4, $3 \mathrm{~mm} \mathrm{MgCl}_{2}$, and $320 \mathrm{~mm}$ sucrose containing a mixture of protease inhibitors (1 mM PMSF, $1.5 \mu \mathrm{M}$ antipain, $1 \mathrm{~mm}$ orthophenantroline, $1 \mu \mathrm{M}$ pepstatin, $1 \mu \mathrm{M}$ aprotinin, $1 \mu \mathrm{M}$ leupeptin, and $1 \mathrm{~mm}$ benzamidine; all from Sigma)] using a Potter-Elveheim homogenizer and a Teflon pestle. The lysate was centrifuged at $1000 \times g$ for 15 min at $4^{\circ} \mathrm{C}$ to remove nuclei and large debris. Thereafter, the supernatant was centrifuged at $100,000 \times g$ for $90 \mathrm{~min}$ at $4^{\circ} \mathrm{C}$ and designated fraction $\mathrm{A}$, corresponding to extracellular components and cytosol. The pellet was solubilized in $30 \mathrm{~mm} \mathrm{NaCl}, 120 \mathrm{~mm}$ glucose, $1 \mathrm{~mm}$ EDTA, and $85 \mathrm{~mm}$ Tris- $\mathrm{HCl}, \mathrm{pH} 7.8$, containing $1 \%(\mathrm{w} / \mathrm{v}) n$-octyl-glucoside replenished with protease inhibitors (1 mM PMSF, $1.5 \mu \mathrm{M}$ antipain, $1 \mathrm{~mm}$ orthophenantroline, $1 \mu \mathrm{M}$ pepstatin, $1 \mu \mathrm{M}$ aprotinin, $1 \mu \mathrm{M}$ leupeptin, and $1 \mathrm{~mm}$ benzamidine) and defined as fraction $\mathrm{B}$, corresponding to membrane proteins.

The purified F3-Fc chimera $(5 \mu \mathrm{g})$ was preincubated with protein A-Sepharose beads (40 $\mu \mathrm{l}$ at $50 \%)$ in PBS at room temperature for $1 \mathrm{hr}$. The beads were rinsed twice in PBS and incubated with $1 \mathrm{ml}$ of (1 $\mathrm{mg} / \mathrm{ml})$ Fraction A at $4^{\circ} \mathrm{C}$ overnight. Alternatively, purified TNfn-Fc proteins $(1 \mu \mathrm{g})$ were preincubated with protein A-Sepharose beads $(25 \mu \mathrm{l}$ at $50 \%$ ) in PBS at room temperature for $1 \mathrm{hr}$. After rinsing twice with PBS, the beads were mixed with $1 \mathrm{ml}$ of $(1 \mathrm{mg}$ of protein $/ \mathrm{ml})$ fraction $\mathrm{B}$ bearing an $\mathrm{NaCl}$ concentration adjusted to $250 \mathrm{~mm}$ and incubated with gentle shaking at $4^{\circ} \mathrm{C}$ overnight. Incubations were ended by spinning the beads, which were washed twice in cold PBS and finally boiled in SDS-PAGE loading buffer. The resulting samples were analyzed by Western blot using the appropriate antibodies.

Indirect immunofluorescence and confocal microscopy. Hippocampal neurons from E18 rats were cultured for $24 \mathrm{hr}$. Cells were fixed for 15 min with PBS and $4 \%(\mathrm{w} / \mathrm{v})$ paraformaldehyde and permeabilized for 90 sec with $0.2 \%(\mathrm{v} / \mathrm{v})$ Triton X-100 at room temperature. After washing with PBS, nonspecific binding sites were blocked with PBS containing 3\% (w/v) BSA for $1 \mathrm{hr}$ at room temperature. F3/contactin was detected by addition of pAbF3 at 1:50 $(120 \mu \mathrm{g} / \mathrm{ml})$ for $1 \mathrm{hr}$ in PBS and $3 \%(\mathrm{w} / \mathrm{v}) \mathrm{BSA}$. For double staining, cells were incubated with monoclonal anti- $\beta$ III tubulin antibody as a neuronal cytoskeleton marker for neurons in PBS and $3 \%(\mathrm{w} / \mathrm{v}) \mathrm{BSA}$ at 1:300 during $1 \mathrm{hr}$ at room temperature. After rinsing, Cy3- and Alexa Fluor 488-conjugated goat secondary antibodies against rabbit and mouse Igs, respectively, were incubated at 1:300 for 45 min in PBS and 3\% BSA at room temperature. After washing in PBS and $\mathrm{H}_{2} \mathrm{O}$, coverslips were mounted in Mowiol (Calbiochem).

Images of cultured neurons were acquired using a confocal laser scanning microscope (LSM 510 inverted; Zeiss). Labeled cells were optically sectioned in the $x-y$ plane (parallel to the substratum) using a differential interference contrast $63 \times$, numerical aperture 1.4 objective and a minimum slice thickness of $0.5 \mu \mathrm{m}$, with multiple scan averaging. Recordings were performed using an argon laser and a helium-neon laser with excitation wavelengths of 488 and $543 \mathrm{~nm}$, respectively. The emission signals were filtered with a Zeiss 515-565 nm filter (Alexa-488 emission) or with a long-pass $595 \mathrm{~nm}$ filter (Cy3 signal). Nonspecific fluorescence was assessed by incubating cells with the secondary fluorescent dye-labeled antibody alone and subtracted from the specific images (Zeiss image software).

Expression of $\mathrm{TN}-\mathrm{C}$ and F3/contactin proteins in the developing hippocampus. Whole heads of E18 rat embryos or newborn rats were fixed by immersion in PBS and 4\% (w/v) paraformaldehyde for $12 \mathrm{hr}$ at $4^{\circ} \mathrm{C}$. Thirty micrometer sections were cut in the frontal plane using a vibratome (Leica, Nussloch, Germany). Nonspecific binding was blocked by incubation for $3 \mathrm{hr}$ at room temperature in PBS and $3 \%(\mathrm{w} / \mathrm{v}) \mathrm{BSA}$. Incubation with primary antibodies using rabbit polyclonal anti-F3/contactin (pAbF3; dilution 1:50, $120 \mu \mathrm{g} / \mathrm{ml}$ ), rabbit polyclonal anti-TN-C (Kaf14; dilution $1: 400,180 \mu \mathrm{g} / \mathrm{ml}$ ), or the rat monoclonal anti-TNfnD $(\mathrm{J} 1 / \mathrm{tn} 2$, clone $578 ; 1: 50)$ was performed overnight on tissue sections at room temperature in PBS and 3\% BSA. After washing in PBS five times during $10 \mathrm{~min}$, Cy3-conjugated polyclonal donkey anti-rabbit antibody (Jackson ImmunoResearch) or biotinylated horse anti-rat antibody (Vectastain; Vector Laboratories, Burlingame, CA) was added at a dilution of 1:1600 in PBS and 3\% BSA for $2 \mathrm{hr}$ at room temperature. In the case of biotinylated antibodies, the signal was amplified and developed with Cy3-coupled streptavidin at 1:1000 in PBS for $15 \mathrm{~min}$ at room temperature. Thereafter, the sections were washed with PBS five times during $10 \mathrm{~min}$, mounted in $60 \%$ glycerol and $40 \%$ PBS, and observed under an epifluorescence microscope (Leica DM RB). The control sections were stained either with the secondary antibody alone or with the preimmune serum obtained from the animal that yielded the pAbF3.

Hippocampal neuron cultures and neurite outgrowth assays. Rat hippocampal neurons were prepared according to standard procedures (Banker and Cowan, 1977). In brief, hippocampi were dissected from E18 Wistar rat fetal brains in Ca- and Mg-free HBSS containing $0.6 \%$ $(\mathrm{w} / \mathrm{v})$ glucose and $7 \mathrm{~mm}$ HEPES, $\mathrm{pH} 7.4$, treated with $0.25 \%(\mathrm{w} / \mathrm{v})$ trypsin for $15 \mathrm{~min}$ at $37^{\circ} \mathrm{C}$, washed three times with HBSS, and dissociated by repeated passages through a fire-polished Pasteur pipette. The cells were cultivated in minimal essential medium (Invitrogen) containing the $\mathrm{N} 2$ supplements plus $0.1 \%(\mathrm{w} / \mathrm{v})$ ovalbumin and $0.1 \mathrm{~mm}$ pyruvate.

Neurite outgrowth from E18 hippocampal neurons plated on DLpolyornithine (Porn)-conditioned supports, coated with TN-C or various TNfn-Fc recombinant proteins, was determined as published previously (Götz et al., 1996). Glass coverslips were treated with $15 \mu \mathrm{g} / \mathrm{ml}$ Porn in $0.1 \mathrm{M}$ borate buffer, $\mathrm{pH} 8.2$, for $1 \mathrm{hr}$ at $37^{\circ} \mathrm{C}$ in a humidified atmosphere. ECM proteins or Fc recombinant proteins were coated at $4 \mu \mathrm{g} / \mathrm{ml}$ for $\mathrm{LN}-1,25 \mu \mathrm{g} / \mathrm{ml}$ for TN-C, and $50 \mu \mathrm{g} / \mathrm{ml}$ for other proteins in $100 \mu \mathrm{l}$ of PBS per coverslip overnight at $37^{\circ} \mathrm{C}$. Coating efficiency was checked by ELISA with a rabbit primary antibody specific for TN-C (Kaf14) at 0.1 $\mu \mathrm{g} / \mathrm{ml}$ and a goat HRP-conjugated anti-rabbit secondary antibody at 0.2 $\mu \mathrm{g} / \mathrm{ml}$ or with a goat-HRP antibody specific for the human Fc tag of the fusion proteins at $0.2 \mu \mathrm{g} / \mathrm{ml}(100 \mu \mathrm{l} /$ coverslip) for $1 \mathrm{hr}$ at room temperature. Protein adsorption was optimal at $20 \mu \mathrm{g} / \mathrm{ml}$. After coating, coverslips were washed twice with N2 media before plating E18 hippocampal neurons at low density $\left(3500\right.$ cells $\left./ \mathrm{cm}^{2}\right)$. When antibodies and F3/contactin peptide were used for perturbation experiments, they were added $2 \mathrm{hr}$ after cell plating. After $24 \mathrm{hr}$ of culture, neurons were fixed by addition of $4 \%(\mathrm{w} / \mathrm{v})$ paraformaldehyde for $15 \mathrm{~min}$, gently washed with PBS, stained using a primary antibody against $\alpha$-tubulin and a secondary antibody conjugated to HRP, and revealed with $0.5 \%(\mathrm{w} / \mathrm{v})$ diaminobenzidine (DAB; in double distilled $\mathrm{H}_{2} \mathrm{O}$ ). The morphometric analysis of neurite lengths was performed with Image Tools software (University of Texas) by measuring the longest neurite from neurons with a process longer than one neuronal cell body diameter. The data were statistically evaluated using one-controlled-factor ANOVA tests, and the significance level was set at $p<0.05$.

$R T-P C R$ analysis of hippocampal TN-C transcripts. Total hippocampal RNA was prepared from E16, E18, P0, and P5 rats using an RNA Plus kit (Q-Biogene). Reverse transcription was performed with $500 \mathrm{ng}$ of hexameric random primers (Amersham Biosciences) and $2.5 \mu \mathrm{g}$ of total 
RNA in a total volume of $29 \mu \mathrm{l}$. These reagents were incubated at $65^{\circ} \mathrm{C}$ for $5 \mathrm{~min}$ and then slowly cooled to room temperature. Subsequently, the reactions were warmed to $37^{\circ} \mathrm{C}$ before the addition of $10 \mu$ l of First Strand buffer (Invitrogen), $2.5 \mu \mathrm{l}$ of $0.1 \mathrm{M}$ dithiothreitol, $2.5 \mu \mathrm{l}$ of $10 \mathrm{~mm}$ dNTPs, $1 \mu \mathrm{l}$ of RNase inhibitor, and $2.5 \mu \mathrm{l}$ of Moloney murine leukemia virus reverse transcriptase (200 IU/ml; Invitrogen). The reactions were incubated for $50 \mathrm{~min}$ at $37^{\circ} \mathrm{C}$ and subsequently at $95^{\circ} \mathrm{C}$ for $5 \mathrm{~min}$. Amplification of isoform-specific TN-C transcripts was achieved by using $2 \mu \mathrm{l}$ of reverse transcriptase reaction per $20 \mu \mathrm{l}$ of PCR with $500 \mathrm{nM}$ concentrations of the appropriate sense and antisense primers (see Table 1). The conditions were as follows: $15 \mathrm{mM}\left(\mathrm{NH}_{4}\right)_{2} \mathrm{SO}_{4}, 2 \mathrm{mM} \mathrm{MgCl}_{2}, 0.5$ mM dNTPs, 60 mM Tris-HCl, pH 8.8, and 1 IU of Taq polymerase (AGS) per reaction. Cycling was performed using a thermocycler (PE-9600; Applied Biosystems) and initiated by a $3 \mathrm{~min}$ denaturation step at $94^{\circ} \mathrm{C}$, followed by 30 cycles of $30 \mathrm{sec}$ at $94^{\circ} \mathrm{C}, 30 \mathrm{sec}$ at $55^{\circ} \mathrm{C}, 90 \mathrm{sec}$ at $72^{\circ} \mathrm{C}$, and a final extension step at $72^{\circ} \mathrm{C}$ for $7 \mathrm{~min}$. Quantification of final PCR products from $1 \%$ agarose gel pictures was undertaken with NIH Image software (Scion Image). Relative RNA concentrations were evaluated in comparison with the expression levels of the housekeeping gene glyceraldehyde-3-phosphate dehydrogenase (primers: 5'-gagtatgtcgtggagtctac and 5'-tgagcttcccgttcagctct), and PCRs were limited to 20 cycles to remain in a linear range.

Analytical procedures. Protein concentrations were determined using the Bio-Rad protein assay. SDS-PAGE was performed with $10 \%$ polyacrylamide gels under reducing or nonreducing conditions, e.g., in the presence or absence of $\beta$-mercaptoethanol. Gels were silver-stained using standard procedures. Western blots were performed by electrotransfer onto Hybond-P polyvinylidene difluoride membranes (Amersham Biosciences). Nonspecific binding sites were blocked with $5 \%(\mathrm{w} / \mathrm{v})$ fat-free milk powder in PBS and $0.1 \%$ (v/v) Tween 20, pH 7.4, for $1 \mathrm{hr}$ at room temperature. After incubation with primary antibodies and washing in PBS and 5\% (w/v) milk powder, bound antibodies were revealed with HRP-conjugated goat anti-rabbit, goat anti-rat, and goat anti-mouse antibodies and developed using enhanced chemiluminescence (Amersham Biosciences).

\section{RESULTS}

\section{Effect of TN-C Fc-recombinant proteins on hippocampal neurons: FNIII domains BD and D6 promote neurite outgrowth}

To improve our understanding of the relationship between TN-C isoform structures and their respective functions, constructs encompassing alternatively spliced FNIII domains were expressed in mammalian cells. The recombinant proteins each contained two contiguous FNIII repeats fused to the Fc fragment of human IgG. The choice of FNIII cassettes was motivated by previous work, which had shown that the alternatively spliced motifs, in particular downstream in the vicinity of the FN III cassette D, harbor neurite outgrowth-promoting properties (Götz et al., 1996; Meiners et al., 1999a). In addition, two constructs containing the FNIII modules CD and D6, chimeras comprising the combinations $\mathrm{A}_{1} \mathrm{D}$ and $\mathrm{BD}$, were generated because the corresponding TN-C isoforms are also expressed in vivo (Joester and Faissner, 1999). In parallel, control chimeras were produced that contained the Fc fragment only and the FN III modules $\mathrm{A}_{1} \mathrm{~A}_{2}$ and 78 , these two last domains being constitutively expressed in $\mathrm{TN}-\mathrm{C}$ (Fig. 1A). These molecular tools offer several advantages. First, compared with previous experiments performed with bacterially expressed proteins, the TNfn-Fc fusions could be stably expressed in eukaryotic cells. Post-translational modifications such as glycosylations might be important for the molecular conformation and, consequently, for protein interactions. Potential $\mathrm{N}$-glycosylation sites of $\mathrm{TN}-\mathrm{C}$ are more abundant within the spliced FN III domains, in particular in $\mathrm{A}_{1}$ and B (Gulcher et al., 1989; NetOGly software, Cambridge, UK). Glycosylation of the TNfn-Fc recombinant proteins was examined by digestion with $\mathrm{N}$-glycosidase $\mathrm{F}$ and hyaluronidase. The results confirmed that the FNIII domains $\mathrm{A}_{1}$ and $\mathrm{B}$ are highly $\mathrm{N}$-glycosylated, whereas other domains did not display significant changes in their apparent molecular weight after enzyme treatment (data not shown). This explains the migration patterns of $\mathrm{TNfnA}_{1}$ - and $\mathrm{TNfnB}$ containing constructs in SDS-PAGE. The corresponding fusions display a higher than predicted molecular weight and tend to migrate as a smear (Fig. 1B). The second major advantage of the $\mathrm{IgFc}$ chimeras is that the fusion proteins are expressed as dimers, which are formed as a result of disulfide bridges between the Ig heavy chain segments of the Fc fragment. Dimerization supposedly enhances the avidity for potential ligands. When TNfn-Fc fusions were resolved by SDS-PAGE under nonreducing conditions, the molecular weight of each chimera was double that observed under reducing conditions, confirming proper assembly of the proteins (Fig. 1B).

To verify the functional capacity of the fusion proteins expressed in the eukaryotic system, neurite outgrowth assays were performed with E18 hippocampal neurons on TNfn-Fc recombinant proteins. Neurons adopted a range of differentiated morphologies dependent on the growth substrate. On poly-DLornithine alone, neurons possessed relatively few short neurites, whereas they developed longer, poorly branched processes on the permissive substrate LN-1. The different TNfn-Fc proteins induced a variety of responses in the hippocampal neurons. Compared with the controls, only purified TN-C, TNfnBD-Fc, and TNfnD6-Fc chimeras acted as stimulating substrates for neurite outgrowth. In contrast, all the other pairs of FNIII domains tested ( $\mathrm{TNfnA}_{1} \mathrm{~A}_{2}-\mathrm{Fc}$, TNfnA $\mathrm{A}_{1} \mathrm{D}-\mathrm{Fc}$, TNfnCD-Fc, and TNfn78$\mathrm{Fc}$ ) yielded the same result as poly-DL-ornithine alone (Fig. 2).

The results of morphometric analysis confirmed earlier observations in that overall neurite length was increased by $40 \%$ on LN-1 and $30 \%$ on purified TN-C. For fusion proteins containing FNIII domains $\mathrm{A}_{1} \mathrm{~A}_{2}, \mathrm{~A}_{1} \mathrm{D}, \mathrm{CD}$, and 78 , the augmentation of neurite lengths did not exceed $10 \%$ and was not significant over background level, whereas both TNfnBD-Fc and TNfnD6-Fc proved as effective as TN-C preparations, promoting lengths by $30 \%$ (Fig. 3). The specificity of outgrowth stimulation exerted by FNIII cassettes was confirmed by antibody perturbation experiments (Table 2). When polyclonal antibodies to TN-C were added to hippocampal neuron cultures, the neurite outgrowthpromoting effects of TN-C- and TNfn-Fc-containing substrates were abolished. In fact, in the presence of pTN-C antibodies, the average neurite length was $35 \mu \mathrm{m}$, and no values superior to 100 $\mu \mathrm{m}$ on $\mathrm{TN}-\mathrm{C}$ or TNfn-Fc recombinant proteins were recorded, similar to the picture obtained on the poly-DL-ornithine control substrate. The presence of the pTN-C antibodies, however, did not modify LN-1-stimulated outgrowth. In this case, the average neurite length was $65 \mu \mathrm{m}$, with $11 \%$ of neurites reaching $>100$ $\mu \mathrm{m}$ (Table 2), analogous to the situation in the absence of TN-C antibodies (Fig. 3). These results support the conclusion that the neurite elongation induced by TN-C and the fusions TNfnBD-Fc and TNfnD6-Fc are specific for the FN III domains. The mapping of a neurite outgrowth promoting area to two FNIII cassettes also suggests that a neuronal receptor mediates the outgrowth promotion signal, and that its binding can be prevented by pTN-C antibodies.

\section{Identification of a neuronal receptor for neurite growth-promoting FNIII-motifs: the cell adhesion molecule F3/contactin selectively binds to TNfnBD-Fc}

To identify complementary receptors of the outgrowth-promoting FNIII domains, a range of neuronal adhesion molecules known to be implicated in the regulation of axon elongation was probed 
Figure 1. Generation and characterization of TNfn-Fc recombinant chimeric fusion proteins. $A$, Schematic diagram of TNfn-Fc recombinant proteins. TN-C displays a modular structure, which consists of the TN-C association domain (TA) in the $\mathrm{N}$-terminal region, 14.5 EGF-like repeats, eight constant FNIII domains, six alternatively spliced FN III domains and a fibrinogen- $\beta / \gamma$-like globe in the $\mathrm{C}$-terminal region. Proteins used in this report consist of fusions of two FNIII domains to the hinge and constant $(\mathrm{CH} 2, \mathrm{CH} 3)$ regions of the human $\mathrm{IgG}$. Processed proteins are secreted as disulfide-linked dimers $(s-s) . B, F c$ recombinant protein expression and purification. Secreted proteins from stably transfected $\mathrm{CHO}$ cell cultures were purified on protein A-Sepharose columns and resolved on 10\% SDS-PAGE under reducing (lanes 1) and nonreducing (lanes 2) conditions. A silver-stained gel is shown. Proteins were also analyzed by Western blots using an HRP-conjugated antibody against the human IgG Fc fragment and revealed by enhanced chemiluminescence (lanes 3 ). Three micrograms of purified protein were loaded per lane.
A

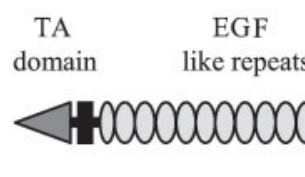

FNIII domains

\section{FNIII domains}

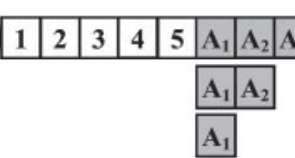
$\mathbf{A}_{1}$
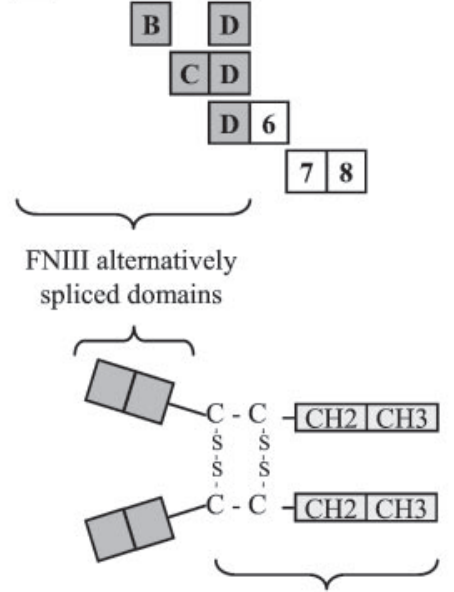

Human immunoglobulin G Fc fragment
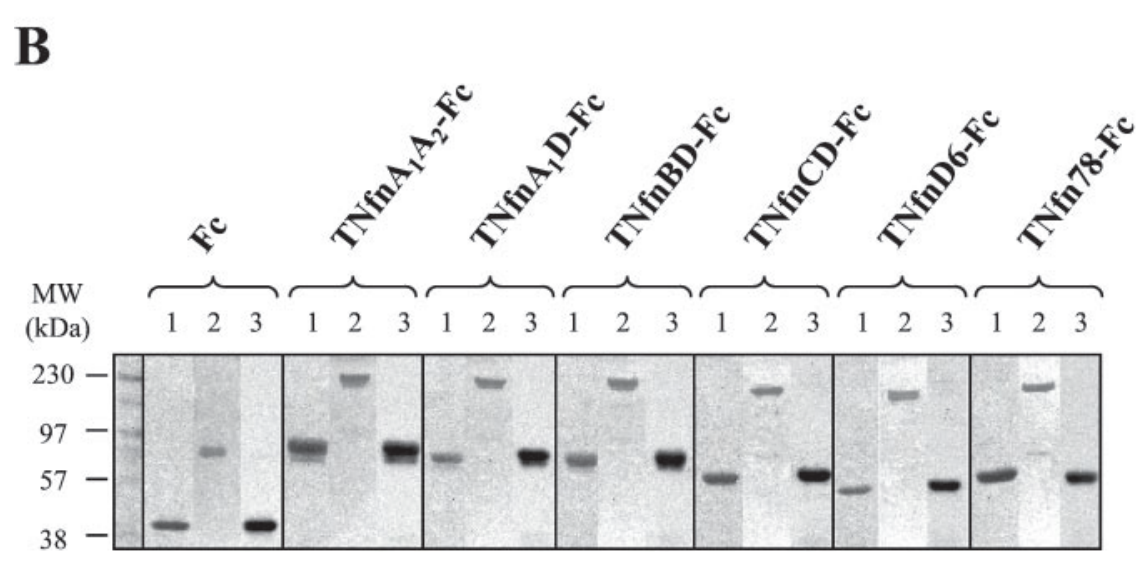

for interactions with TN-C and derived fusion proteins. Several members of the IgCAM superfamily that were available as Fc fusions were tested in bead aggregation assays, namely F3-Fc, L1/NgCAM-Fc, TAG-1/axonin-Fc, and neural cell adhesion molecule-Fc (Buttiglione et al., 1998; Chen et al., 1999). Fluorescent microspheres covalently conjugated with goat anti-human Fc fragment antibodies were incubated with conditioned medium containing various Fc recombinant proteins. Aggregation assays were performed by mixing yellow-green microspheres conjugated to TNfn-Fc proteins and red beads coated with the different CAM-Fc fusion proteins. In the case of intermolecular interactions between different coated chimeric proteins, the formation of mixed aggregates composed of the corresponding beads should occur. Alternatively, aggregates of a single type of bead may occur for proteins with homophilic adhesive properties, as could indeed be observed for the cell adhesion molecule L1/neuron-glia CAM (data not shown). In an initial screen, the different TNfn-Fc chimeras were presented to each available IgCAM-Fc construct. Only one of the molecules tested, the glycosyl-phosphatidylinositol (GPI) membrane-anchored F3/contactin protein, bound to one of the TNfn-Fc recombinant proteins, namely TNfnBD-Fc
(Fig. $4 A$; data not shown for other CAM). All the other combinations of paired FNIII modules, e.g., TNfnA $\mathrm{A}_{1} \mathrm{~A}_{2}-\mathrm{Fc}, \mathrm{TNfnA}_{1} \mathrm{D}$ $\mathrm{Fc}$, TNfnCD-Fc, TNfnD6-Fc, and TNfn78-Fc, proved inert in this assay (Fig. 4A). The quantitative analysis of mixed aggregates evaluated from 20 visual fields reinforced this conclusion. An average of 175 mixed aggregates were counted when beads coated with TNfnBD-Fc and F3-Fc were presented to each other, whereas the number of bead clusters was in the range of 25 for all other combinations (Fig. 4B). Moreover, the formation of aggregates could be prevented by preincubating the F3-Fc-conjugated beads with $20 \mu \mathrm{g}$ of polyclonal anti-F3 antibodies (Fig. $4 C$ ). These results highlight that the cell adhesion molecule F3/contactin specifically recognizes the FNIII BD domains and none of the other combinations tested.

To examine whether the interaction between F3/contactin and TN-C revealed by the bead aggregation assay also occurs with the native proteins expressed in vivo, pull-down assays with brain lysates were performed. Fc fragments (control) or F3-Fc chimeras attached to protein A-Sepharose beads were incubated with P0-P7 mouse brain extracts. Complexes obtained were analyzed by Western blotting using different anti- 

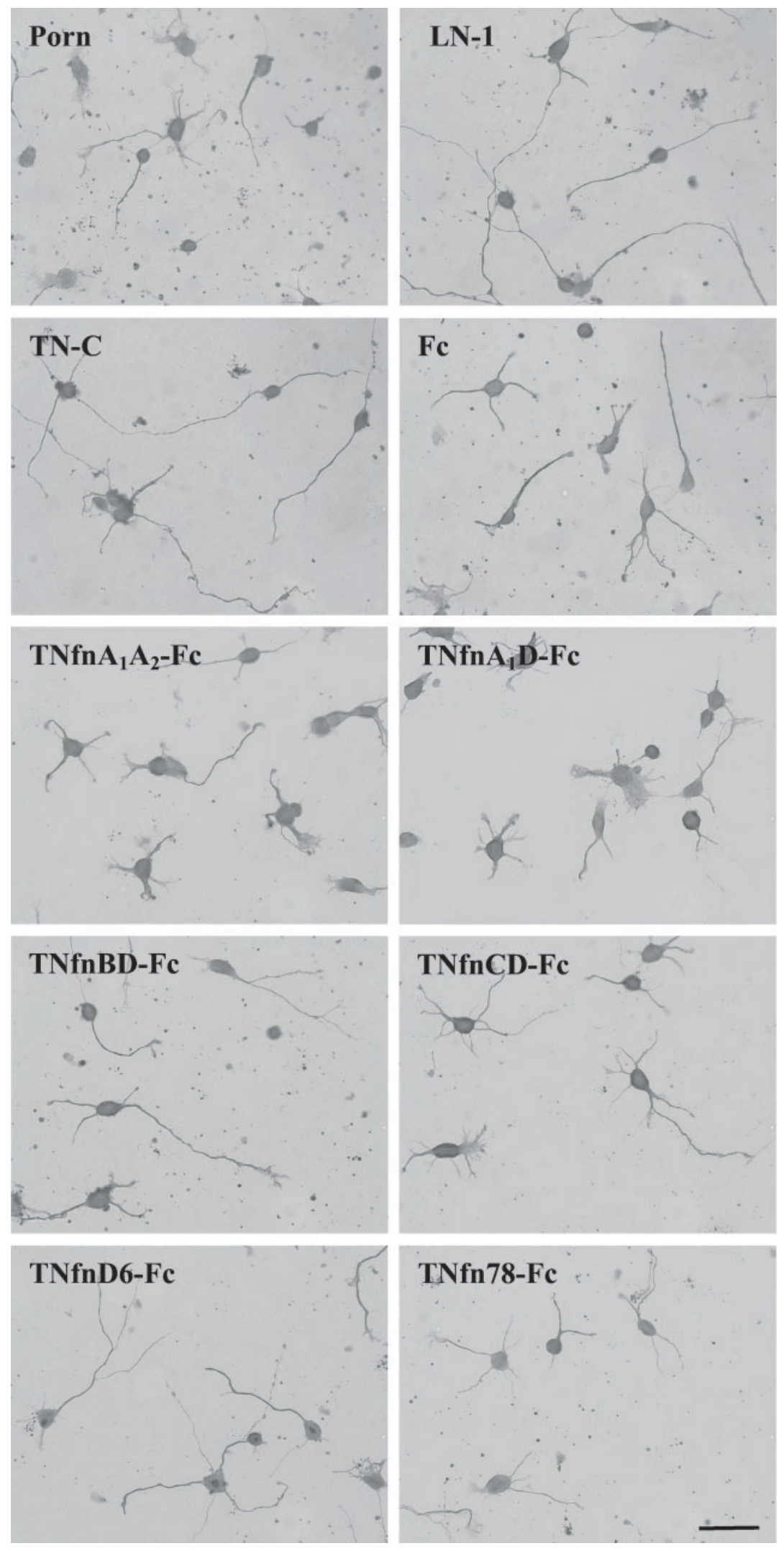

Figure 2. Morphology of E18 hippocampal neurons growing on control and TNfn-Fc substrates. Cells were cultivated for $24 \mathrm{hr}$ on coverslips coated with different proteins. The minimal substrate defined as the negative control consisted of Porn, and the permissive substrate defined as the positive control was coated with $4 \mu \mathrm{g} / \mathrm{ml}$ $\mathrm{LN}-1$. Other growth supports consisted of purified TN-C (applied at $25 \mu \mathrm{g} / \mathrm{ml}$ ) or the following TNfn-Fc chimeric proteins coated at $50 \mu \mathrm{g} / \mathrm{ml}$ : Fc-fragment alone, TNfnA $A_{1} \mathrm{~A}_{2}-\mathrm{Fc}$, TNfnA $\mathrm{A}_{1}$ D-Fc, TNfnBD-Fc, TNfnCDFc, TNfnD6-Fc, and TNfn78-Fc. Scale bar, $30 \mu \mathrm{m}$. bodies against TN-C (Fig. 5A). When blots were developed with polyclonal TN-C antibodies, TN-C was only documented in F3-Fc precipitates. This interaction is specific for F3/ contactin, because no signal was detected using the Fc frag- ment alone as a control ligand. The expected pattern was observed for TN-C glycoproteins, with the detection of two major bands at 190 and $220 \mathrm{kDa}$. This result was confirmed with the monoclonal antibody $\mathrm{J} 1 / \mathrm{tn} 3$, which maps to the EGF- 


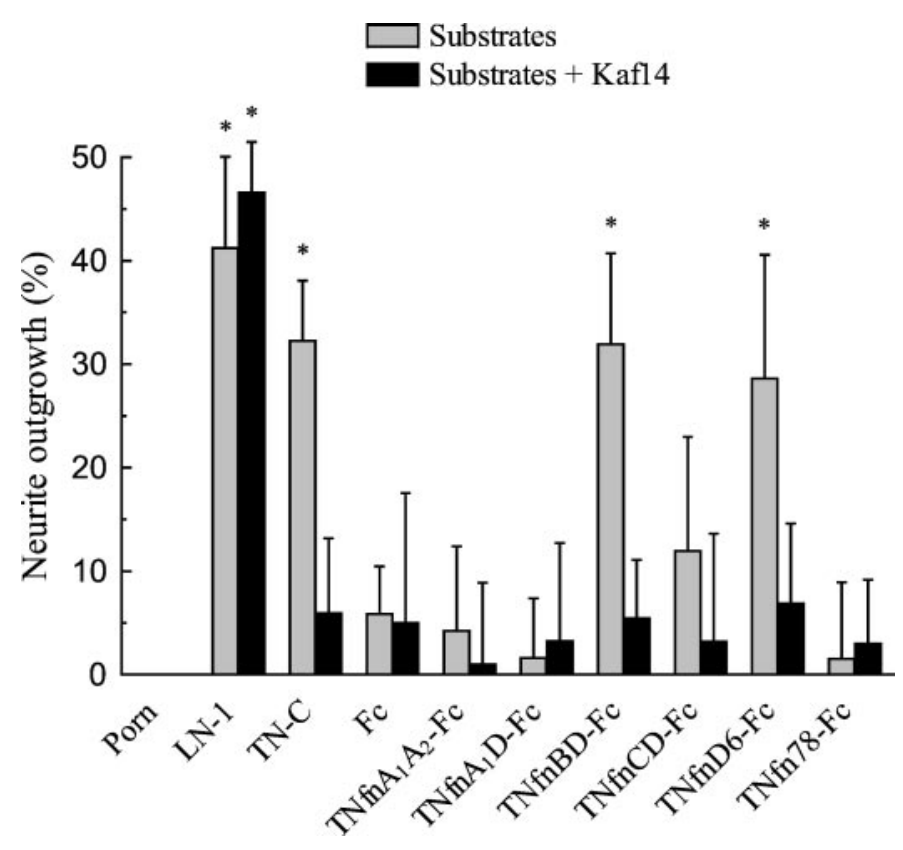

Figure 3. Percentage of neurite length increase of E18 hippocampal neurons cultivated on ECM- and Fc-recombinant proteins. Control experiments were performed in parallel with perturbation assays in the presence of polyclonal anti-TN-C antibodies. Cells were fixed and subsequently stained for $\alpha$-tubulin using DAB. The lengths of the longest neurites of neurons were measured (150-200 neurons were counted per condition). The distributions of process lengths were compared for the different substrates, both in the presence and in the absence of antibodies. Likewise, length distributions on a given substrate were evaluated for the different treatments (ANOVA test with a single variable factor; significance, ${ }^{*} p<0.01$ ). Data of experiments for each condition are summarized in Table 2. Bars represent the mean values $\pm \mathrm{SD}$ expressed as the percentage relative to Porn control values (set at $0 \%$ ).

type repeats. Interestingly, the higher $M_{\mathrm{r}}$ variants, which correspond to the largest $\mathrm{TN}-\mathrm{C}$ isoforms or to isoforms that are highly glycosylated, seem to be preferentially precipitated. This observation was supported by using the monoclonal antibodies $\mathrm{J} 1 / \operatorname{tn} 1$ and $\mathrm{J} 1 / \mathrm{tn} 2$, which recognize the FNIII domains $\mathrm{A}_{2}$ and $\mathrm{D}$, respectively, confirming the presence of both spliced modules in the precipitates (Fig. $5 A$ ). In a series of reversed experiments, pull-down assays were also realized with protein A-Sepharose beads coupled to TNfn-Fc recombinant proteins. Native F3/contactin was complexed from mouse brain membrane lysates withTNfnBD-Fc but not by the other constructs, consistent with the results of the bead aggregation assay (Fig. 5B). Hence, a binding site of F3/contactin maps to the FNIII-cassettes $\mathrm{BD}$ of TN-C.

\section{The TNfnBD-Fc-promoting effect on hippocampal neurons is mediated by the neuronal F3/contactin receptor}

Because both the FNIII BD domains and the cell adhesion molecule F3/contactin are known to be involved in regulation of neurite outgrowth, functional tests were undertaken to demonstrate that BD-induced neurite outgrowth promotion of hippocampal neurons is mediated by the receptor F3/contactin. Immunocytology performed with $\mathrm{pF} 3$ antibodies confirmed the expression of the cell adhesion molecule F3/contactin on the surface of hippocampal neurons in vitro. Previous experiments have revealed that F3/contactin is expressed by granule cell neurons from cerebellum and by hippocampal neurons cultured for
1-4 d on a substrate coated with laminin-1 (Buttiglione et al., 1996). Therefore, the present investigations focused on early developmental states of hippocampal neurons growing for up to $24 \mathrm{hr}$ on poly-DL-ornithine. In double-staining studies with monoclonal anti- $\beta$ III-tubulin to demarcate neurons and neurites, all cell bodies were found to be positive for F3/contactin, and staining was particularly strong on membranes. In a subpopulation of neurons, however, a heterogeneous distribution of F3/contactin on cell processes could be distinguished. Thus, only cell bodies and growth cones of bipolar neurons expressed F3/contactin, whereas the fibers proper were barely stained (Fig. 6A, top). When neurons were more differentiated, growth cone staining was diminished, but F3/contactin-positive neurite segments were observed, which corresponded to regions of developing spikes or the initiation of collateral branches (Fig. 6 $\mathrm{A}$, bottom). This observation is complemented by the finding that staining in fully developed collaterals was diminished (Fig. 6 $\mathrm{A}$, top).

To characterize more precisely the functional significance of TN-C-F3/contactin interactions for neurite outgrowth, antibody perturbation assays were performed using polyclonal anti-F3/ contactin. The antibodies were added to neuronal cultures $2 \mathrm{hr}$ after plating to block the accessibility of the F3/contactin receptor for its interaction site in TN-C. Neurite elongation of hippocampal neurons was reduced to control levels when the chimeric protein TNfnBD-Fc was used as a substrate, whereas neurite outgrowth promotion caused by $\mathrm{TN}-\mathrm{C}$ or the fusion protein TNfnD6-Fc was not compromised (Table 2, Fig. 6B). The blocking effect was neutralized when the antibodies were preincubated with the peptide used for immunization before addition to the hippocampal neuronal cultures, which restored the TNfnBD-Fcdependent promotion of neurite outgrowth (Table 2, Fig. 6B). These results strongly support the conclusion that the interaction between TNfnBD-Fc and its neuronal receptor F3/contactin is functionally important and implicated in the stimulation of hippocampal neuron outgrowth in vitro.

\section{A potential role in vivo for the interaction between $\mathrm{TN}$ - C fibronectin BD domains and the cell adhesion molecule F3/contactin}

Next we examined whether the induction of neurite outgrowth by the TN-C fibronectin BD domains observed in vitro, via its ligand F3/contactin, could be correlated with physiological processes during hippocampal development. As a first step toward elucidating the potential role of this interaction for hippocampal development in vivo, the expression of F3/contactin was examined in the hippocampus using immunohistology. In the E18 rat hippocampus, both TN-C and F3/contactin are expressed, but their patterns of expression do not show a perfect overlap. The TN-C expression pattern is characterized by a strong immunoreactivity in the subplate, in the marginal zones and in the dentate marginal zone bordering the dentate gyrus. In other regions, staining appeared weaker or absent, in particular, in the hippocampal layer, where pyramidal neurons are already present at this developmental stage. For F3/contactin, the distribution was more homogeneous, except in layers of the ventricular and subventricular zones, where staining was weaker (Fig. 7). Thus, TN-C and F3/contactin do not exhibit a perfect overlap, but these two molecules colocalize in numerous regions of the hippocampus, principally in the subplate and the marginal zones. Their localization in these regions in a dynamic pattern correlates with neurite elongation and the establishment of connections during maturation of the hippocampus. Indeed, the expression patterns 


\begin{tabular}{|c|c|c|c|c|c|c|c|c|}
\hline Condition & Substrate & $N$ & $n$ & $\begin{array}{l}\text { Neurite length, } \\
\text { mean } \pm \operatorname{SEM}(\mu \mathrm{m})\end{array}$ & $\begin{array}{l}\text { Minimum } \\
(\mu \mathrm{m})\end{array}$ & $\begin{array}{l}\text { Maximum } \\
(\mu \mathrm{m})\end{array}$ & $\begin{array}{l}\text { Neurites }>100 \\
\mu \mathrm{m}(\%)\end{array}$ & ANOVA test* \\
\hline \multicolumn{9}{|c|}{ Neurite outgrowth assays on TNfnIII-Fc recombinant proteins } \\
\hline \multirow[t]{10}{*}{ Control } & Porn & 5 & 811 & $39.2 \pm 2.4$ & 10 & 133 & 0.95 & NS \\
\hline & LN-1 & 4 & 654 & $67.9 \pm 11.8$ & 14 & 240 & 14.2 & +++ \\
\hline & $\mathrm{TN}-\mathrm{C}$ & 3 & 515 & $58.9 \pm 9.4$ & 10 & 167 & 9.59 & +++ \\
\hline & $\mathrm{Fc}$ & 5 & 751 & $41.7 \pm 3.7$ & 10 & 172 & 1.28 & NS \\
\hline & $\mathrm{TNfnA}_{1} \mathrm{~A}_{2}-\mathrm{Fc}$ & 5 & 691 & $41.1 \pm 4.5$ & 11 & 156 & 1.14 & NS \\
\hline & $\mathrm{TNfnA}_{1} \mathrm{D}-\mathrm{Fc}$ & 5 & 752 & $39.9 \pm 3.4$ & 12 & 139 & 0.11 & NS \\
\hline & TNfnBD-Fc & 5 & 826 & $58.6 \pm 11.2$ & 11 & 191 & 7.89 & +++ \\
\hline & TNfnCD-Fc & 5 & 787 & $45.1 \pm 7.1$ & 11 & 147 & 2.47 & + \\
\hline & TNfnD6-Fc & 5 & 801 & $56.1 \pm 10.8$ & 11 & 242 & 6.69 & +++ \\
\hline & TNfn78-Fc & 5 & 835 & $39.9 \pm 4.1$ & 11 & 154 & 0.63 & NS \\
\hline \multirow[t]{10}{*}{ Kaf14 $(30 \mu \mathrm{g} / \mathrm{ml})$} & Porn & 4 & 583 & $33.8 \pm 1.6$ & 10 & 125 & 0.12 & NS \\
\hline & LN-1 & 4 & 637 & $63.6 \pm 5.9$ & 10 & 245 & 11.2 & +++ \\
\hline & $\mathrm{TN}-\mathrm{C}$ & 3 & 247 & $36.3 \pm 2.2$ & 11 & 131 & 0.49 & NS \\
\hline & $\mathrm{Fc}$ & 4 & 624 & $36.0 \pm 4.6$ & 10 & 125 & 0.66 & NS \\
\hline & $\mathrm{TNfnA}_{1} \mathrm{~A}_{2}-\mathrm{Fc}$ & 4 & 566 & $34.3 \pm 3.4$ & 10 & 111 & 0.48 & NS \\
\hline & $\mathrm{TNfnA}_{1} \mathrm{D}-\mathrm{Fc}$ & 4 & 600 & $34.2 \pm 4.0$ & 10 & 118 & 0.36 & NS \\
\hline & TNfnBD-Fc & 4 & 553 & $35.8 \pm 2.2$ & 10 & 112 & 0.26 & NS \\
\hline & TNfnCD-Fc & 4 & 620 & $35.2 \pm 3.8$ & 11 & 123 & 0.34 & NS \\
\hline & TNfnD6-Fc & 4 & 594 & $36.4 \pm 3.1$ & 10 & 121 & 0.23 & NS \\
\hline & TNfn78-Fc & 4 & 483 & $34.9 \pm 1.6$ & 10 & 91 & 0 & NS \\
\hline \multicolumn{9}{|c|}{ Neurite outgrowth anti-F3 antibody perturbation assays on TNfnIII-Fc recombinant proteins } \\
\hline \multirow[t]{10}{*}{ pAbF3 $(30 \mu \mathrm{g} / \mathrm{ml})$} & Porn & 5 & 779 & $37.9 \pm 4.9$ & 10 & 125 & 0.86 & NS \\
\hline & LN-1 & 4 & 654 & $71.2 \pm 8.8$ & 12 & 275 & 15.1 & +++ \\
\hline & $\mathrm{TN}-\mathrm{C}$ & 3 & 569 & $53.9 \pm 7.3$ & 10 & 243 & 4.82 & +++ \\
\hline & $\mathrm{Fc}$ & 5 & 729 & $39.9 \pm 6.6$ & 11 & 152 & 1.41 & NS \\
\hline & $\mathrm{TNfnA}_{1} \mathrm{~A}_{2}-\mathrm{Fc}$ & 5 & 809 & $39.7 \pm 3.4$ & 10 & 132 & 0.82 & NS \\
\hline & $\mathrm{TNfnA}_{1} \mathrm{D}-\mathrm{Fc}$ & 5 & 774 & $39.4 \pm 4.7$ & 12 & 113 & 0.97 & NS \\
\hline & TNfnBD-Fc & 5 & 825 & $42.8 \pm 6.2$ & 11 & 161 & 1.21 & + \\
\hline & TNfnCD-Fc & 5 & 811 & $41.9 \pm 5.9$ & 10 & 135 & 1.16 & + \\
\hline & TNfnD6-Fc & 5 & 834 & $53.5 \pm 11.1$ & 11 & 184 & 6.57 & +++ \\
\hline & TNfn78-Fc & 5 & 747 & $38.4 \pm 4.3$ & 10 & 120 & 0.66 & NS \\
\hline \multirow[t]{10}{*}{ pAbF3 + peptide $(30+10 \mu \mathrm{g} / \mathrm{ml})$} & Porn & 4 & 636 & $39.9 \pm 3.1$ & 13 & 145 & 0.55 & NS \\
\hline & LN-1 & 4 & 638 & $73.3 \pm 13.3$ & 10 & 346 & 20 & +++ \\
\hline & TN-C & 3 & 488 & $57.3 \pm 2.5$ & 10 & 201 & 8.02 & +++ \\
\hline & $\mathrm{Fc}$ & 4 & 682 & $41.1 \pm 6.5$ & 11 & 140 & 1.4 & NS \\
\hline & $\mathrm{TNfnA}_{1} \mathrm{~A}_{2}-\mathrm{Fc}$ & 4 & 595 & $43.1 \pm 4.8$ & 11 & 128 & 0.85 & NS \\
\hline & $\mathrm{TNfnA}_{1} \mathrm{D}-\mathrm{Fc}$ & 4 & 635 & $40.4 \pm 1.8$ & 10 & 124 & 0.36 & NS \\
\hline & TNfnBD-Fc & 4 & 675 & $57.8 \pm 5.4$ & 10 & 163 & 6.9 & +++ \\
\hline & TNfnCD-Fc & 4 & 601 & $44.8 \pm 7.7$ & 10 & 167 & 2.35 & + \\
\hline & TNfnD6-Fc & 4 & 638 & $56.4 \pm 7.1$ & 10 & 208 & 7.25 & +++ \\
\hline & TNfn78-Fc & 4 & 628 & $40.5 \pm 4.6$ & 10 & 125 & 0.99 & NS \\
\hline
\end{tabular}

$N$, Number of independent experiments; $n$, number of total measured neurites.

${ }^{*}$ ANOVA test with risk, $p=0.05$. Significance:,$+++ p<0.001 ;++, p<0.003 ;+, p<0.05$; NS, not significant, $p>0.05$.

of TN-C and F3/contactin correspond to periods in which neural precursor migration, process outgrowth, and the formation of connections between intrahippocampal and extrahippocampal structures occur.

Second, we used RT-PCR analysis to identify the splicing variants of TN-C expressed during hippocampal development. Total RNA preparations from E16, E18, P0, and P5 hippocampi were tested for the amplification of the pairs of FN III repeats 56, $\mathrm{A}_{1} \mathrm{~A}_{2}, \mathrm{~A}_{1} \mathrm{D}, \mathrm{BD}, \mathrm{CD}, \mathrm{D} 6$, and 78 (Fig. $8 A$ ). The primer pair for the 56 domains generated seven bands corresponding to insertions of a various number of spliced exons, ranging from the shortest isoform (no insert between FNIII domains 5 and 6) to the longest one (all FNIII domains present). This PCR pattern and the semiquantitative analysis of the emerging PCR products showed that all possible sizes of isoforms, e.g., containing zero to six spliced domains, could be found during this period of hippocampal development (Fig. $8 A$ ). The distribution of TN-C variants obtained with the primers for 7 and 8, which correspond to constitutively expressed FNIII exons, was stable during the states investigated, suggesting that the expression of TN-C was constant in the developing hippocampus between E16 and P5. It appeared, however, that transcripts containing the combinations of FN III domains $\mathrm{A}_{1} \mathrm{~A}_{2}$ and $\mathrm{A}_{1} \mathrm{D}$ were relatively rare between $\mathrm{E} 18$ and 

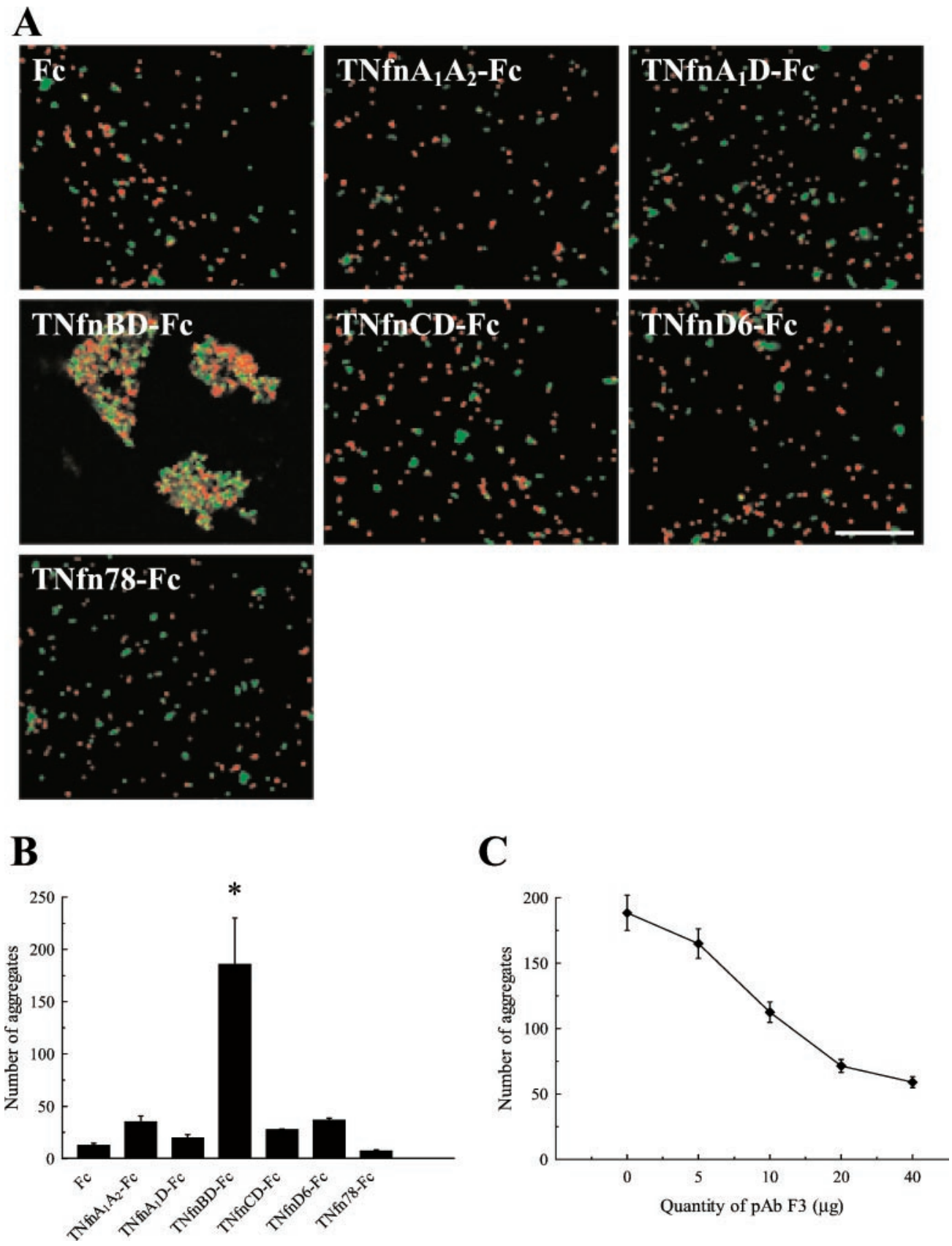
scribed previously $(n=2)$.

P5. These results suggest that $A_{1}$ is a rarely spliced repeat, because FNIII motif $\mathrm{D}$ was detected at a high frequency in most TN-C-messages, consistent with earlier observations relating to the P6 mouse cerebellum (Joester and Faissner, 1999). No variations were detected for isoforms containing the FN III D6 domains, but with regard to $\mathrm{BD}$ and $\mathrm{CD}$, the results revealed that the patterns of these two combinations changed approximately at birth (Fig. $8 B$ ). In fact, the frequency of variants containing adjacent FNIII domains B and D decreased progressively from E16 to P5. This phenomenon could be explained in part by the elimination of the B exon in TN-C variants, but remarkably, the $\mathrm{BD}$ combination decreases in favor of the isoforms containing the three-FNIII domain combination BCD. These observations suggest that the FNIII exon $\mathrm{C}$ is postnatally inserted between the spliced domains $\mathrm{B}$ and $\mathrm{D}$, which explains the increase of $\mathrm{CD}$ variants after birth. Hence, it seems that variants with the combination $\mathrm{BD}$ represent a large proportion of $\mathrm{TN}-\mathrm{C}$ isoforms in embryos during hippocampal development. These may represent determining ECM factors incorporating an axonal growth stimulus in the presence of the neuronal receptor F3/contactin during the period of axon outgrowth and pathfinding in the developing hippocampus, which terminates shortly after birth.

\section{DISCUSSION}

Using Fc-recombinant proteins as molecular tools, we have demonstrated a novel interaction between the FNIII BD domains of TN-C and the GPI-membrane-anchored adhesion glycoprotein F3/contactin of the Ig superfamily. Functionally, the distal area of the alternatively spliced segment of TN-C caused neurite out- 

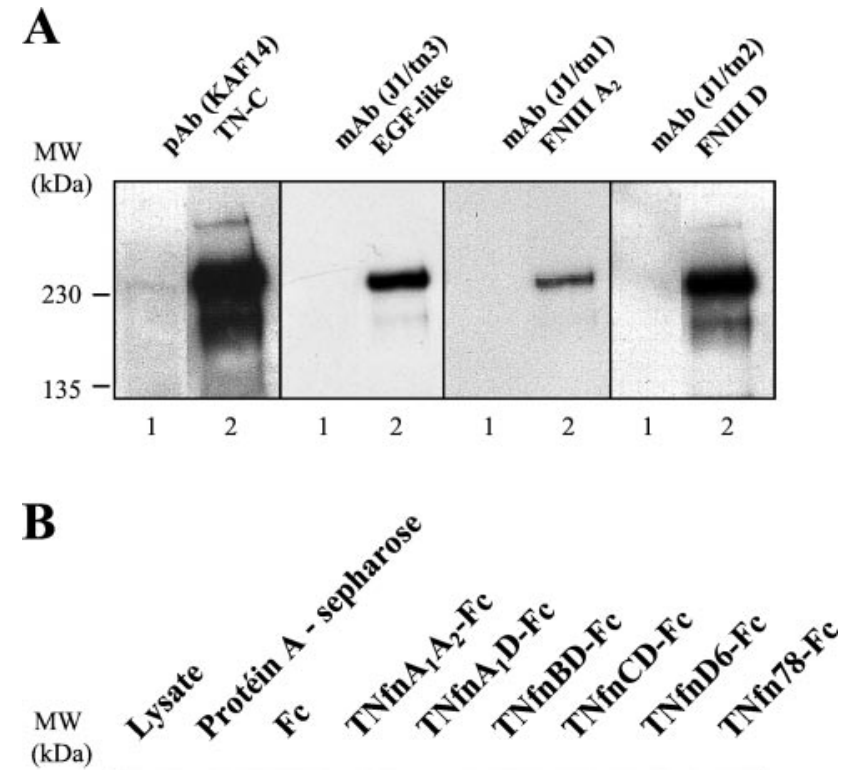

(kDa)

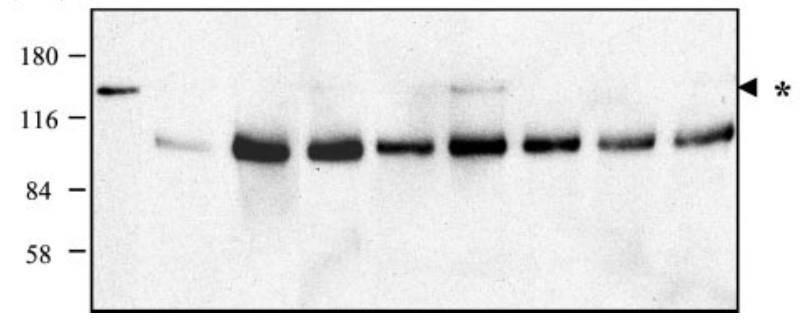

Figure 5. Pull-down assays from P7-P14 mouse brain homogenates using Fc recombinant proteins. $A$, Immunoblot analysis of TN-C in the F3-Fc affinity isolates. F3-Fc fusion protein or a plain Fc fragment (control) coupled to protein A-Sepharose was incubated with $0.5 \mathrm{mg}$ of proteins from total brain lysate, and complexes were analyzed on Western blots. Fc complex (lanes 1) and F3-Fc complex (lanes 2) were loaded on $10 \%$ SDS-PAGE gels under reducing conditions and revealed after Western blotting using different antibodies against $\mathrm{TN}-\mathrm{C}$ : rabbit polyclonal antibodies (Kaf14), and the rat monoclonal antibodies $\mathrm{J} 1 / \mathrm{tn} 3$ (clone 630, recognizing the EGF-type repeats), J1/tn1 (clone 576, specific for FNIIIrepeat $\mathrm{A}_{2}$ ), and $\mathrm{J} 1 / \mathrm{tn} 2$ (clone 578 , specific for FNIII domain $\mathrm{D}$ ). $B$, TNfn-Fc pull-down assays of F3/contactin from whole-brain membrane lysate. Equal amounts of the TNfn-Fc constructs were attached to protein A-Sepharose and incubated with postnatal mouse brain membrane lysate. Protein A-Sepharose alone represents a control without antibody; the Fc fragment is the control construct without any TN-C sequence. The blot was probed with the monoclonal antibody directed against F3/contactin/ $\mathrm{F} 11(\mathrm{mAbF} 3)$. The $130 \mathrm{kDa}$ F3 band is precipitated by TNfnBD-Fc (*). The first lane shows a Western blot performed with F3/contactinantibodies on the whole-brain lysate used for the assay to indicate the position of the cell adhesion molecule. The nonspecific band at $100 \mathrm{kDa}$ is recognized by the anti-mouse secondary antibody alone.

growth promotion of E18 hippocampal neurons. Evidence is provided here that neurite extension induced by the FN III BD domains of TN-C is specifically launched by the interaction with the F3/contactin glycoprotein. This cell adhesion molecule is the first complementary neuronal receptor for TN-C involved in neurite outgrowth promotion. In addition, we have shown that the expression of F3/contactin in the embryonic hippocampus is closely correlated with the establishment of neuronal circuits and the expression of TN-C transcripts containing the combination $\mathrm{BD}$. These observations suggest that TN-C could play an important role during early stages of hippocampal development.

\section{Hippocampal neurite outgrowth is induced by FNIII domains BD and D6 of TN-C}

As described in previous studies, the alternatively spliced FNIII domains of TN-C, in particular BD and D6, promote neurite outgrowth (Götz et al., 1996; Meiners et al., 1999a,b; 2001). Our observations are in agreement with the results obtained using recombinant proteins expressed in bacteria. The effect on outgrowth observed with TNfnBD-Fc and TNfnD6-Fc chimeras is equivalent to the one recorded with purified TN-C. Moreover, the present study emphasizes a functional significance of the combinatorial variability of FN III exons in the differential regulation of $\mathrm{TN}-\mathrm{C}$ interactions with its receptors. Only recombinant proteins containing FNIII domain D associated with FNIII modules B and 6 are able to sustain process elongation. Previous experiments have shown that perturbation studies using a monoclonal antibody against D abolish the effects of TN-C on neurite elongation (Lochter et al., 1991, Meiners et al., 1999a). A site for promotion of neurite outgrowth by $\mathrm{TN}-\mathrm{C}$ has recently been characterized as a peptide within the FNIII domain D (Meiners et al., 2001). It represents an interesting issue whether this peptide derived from TN-C domain D, which is highly conserved in several species, is involved in neurite outgrowth promotion enacted by TNfnBD-Fc. This question could not, however, be approached by a competition assay, because the peptide by itself stimulates neurite outgrowth when added to culture media in soluble form and enhances neurite lengths on D-containing substrates (Meiners et al., 2001). On the other hand, the singular cassette D expressed as recombinant protein was ineffective in stimulating outgrowth (Dörries et al., 1996). Thus, although the stimulating effect for several types of neurons is attributable to the $\mathrm{D}$ domain, it is plausible that this activity is modulated by the presence of neighboring FNIII domains in the different isoforms of TN-C. In light of these observations, the D domain appears necessary but not sufficient to stimulate outgrowth from hippocampal neurons. The additional presence of either domain B or 6 in the vicinity of $\mathrm{D}$ is required to induce specific outgrowth promotion. This conclusion is underscored by the observation that neither FNIII domain $\mathrm{A}_{1}$ nor $\mathrm{C}$ had any effect when associated with $\mathrm{D}$. Thus it appears that neurite outgrowth stimulation depends not only on the presence of an active site within FNIII motif $\mathrm{D}$ but also on the modulation of the interaction with one or several neuronal receptors caused by other domains. The presence of neighboring FNIII modules might play a role in the accessibility of the peptide sequence that induces stimulation of outgrowth.

\section{A functional receptor for FNIII BD domains of TN-C: outgrowth promotion is mediated by the cell adhesion molecule F3/contactin}

To identify $\mathrm{TN}-\mathrm{C}$ interaction sites, a mapping strategy using recombinant proteins was implemented to improve our understanding of the mechanisms through which such interactions may occur. The present study documents in a first step that TN-C glycoproteins, containing different alternatively spliced FNIII domains, can interact with F3/contactin. This binding involves the specific participation of FNIII BD domains. Hence it seems that two successive and specific FNIII domains are necessary in TN-C isoforms for outgrowth promotion and that FNIII repeat pairs BD and D6 act on two different receptors, with B presumably being the only FNIII domain that can facilitate the interaction with the F3/ contactin receptor. The antibody inhibition studies with antiF3/contactin clearly show that neurite extension induced by 


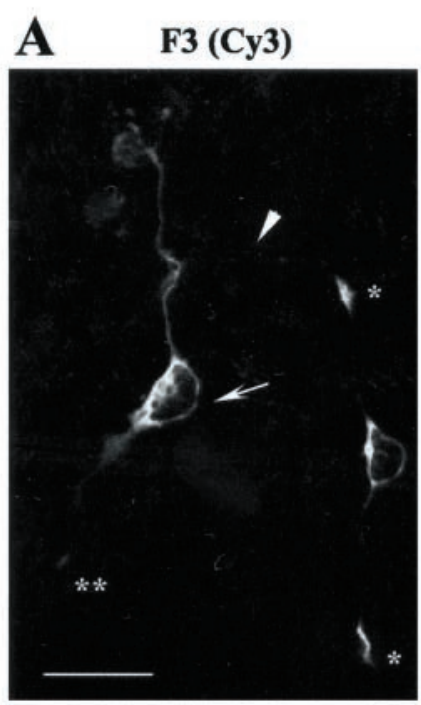

B III-tubulin (Alexa 488)
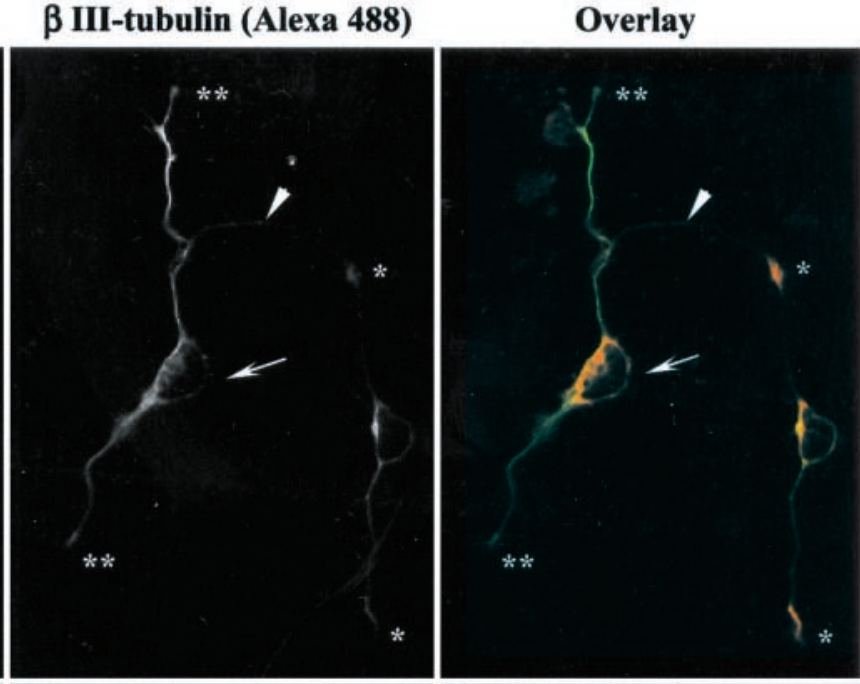
immunofluorescence of anti-F3/contactin serum (pAbF3) visualized with a Cy3conjugated secondary antibody (left column) and monoclonal anti- $\beta$ III-tubulin revealed with an Alexa-conjugated secondary antibody (middle column) was performed on cells after $24 \mathrm{hr}$ in culture. Overlays were obtained by the superposition of images with each fluorochrome (right column). Different patterns of F3/ contactin distribution in neuronal membranes were observed in correlation with cell morphology: in general, neurons display staining for $\mathrm{F} 3$ /contactin on the cell body (arrows). Furthermore, bipolar neurons strongly express $\mathrm{F} 3$ /contactin on growth cones $\left(^{*}\right)$, whereas other neurons exhibit only a weak signal on growth cones $(* *)$. Specific labeling detected on circumscribed neurite segments corresponds to branch points (double arrowheads), with the collaterals being negative for F3/contactin (single arrowheads). Scale bar, $20 \mu \mathrm{m} . B$, Percentage of neurite length increase of hippocampal neurons cultivated on ECM and Fc recombinant proteins in the presence of anti-F3/contactin antibody. Neurons were maintained under the same conditions as described for Figure 3. Perturbation assays were realized using pAbF3 directed at the $\mathrm{N}$ terminus of the glycoprotein F3/contactin or using the same polyclonal antibody after preincubation with the peptide used for immunization. The distributions of process lengths were analyzed using an ANOVA test with a single variable factor for the different substrates under the same condition (in the presence or absence of antibodies), and for one condition on the same substrate. Significance, ${ }^{*} p<0.01$. Data of experiments for both conditions are summarized in Table 2. Bars represent the mean values \pm SD expressed as the percentage relative to Porn control values (set at $0 \%$ ).
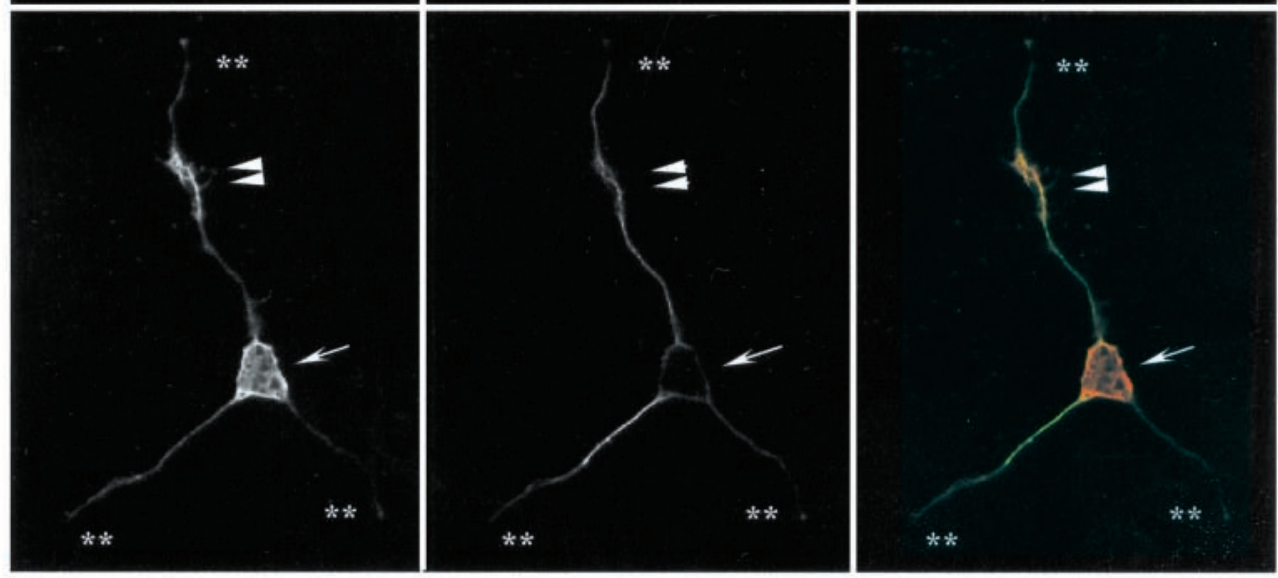

B

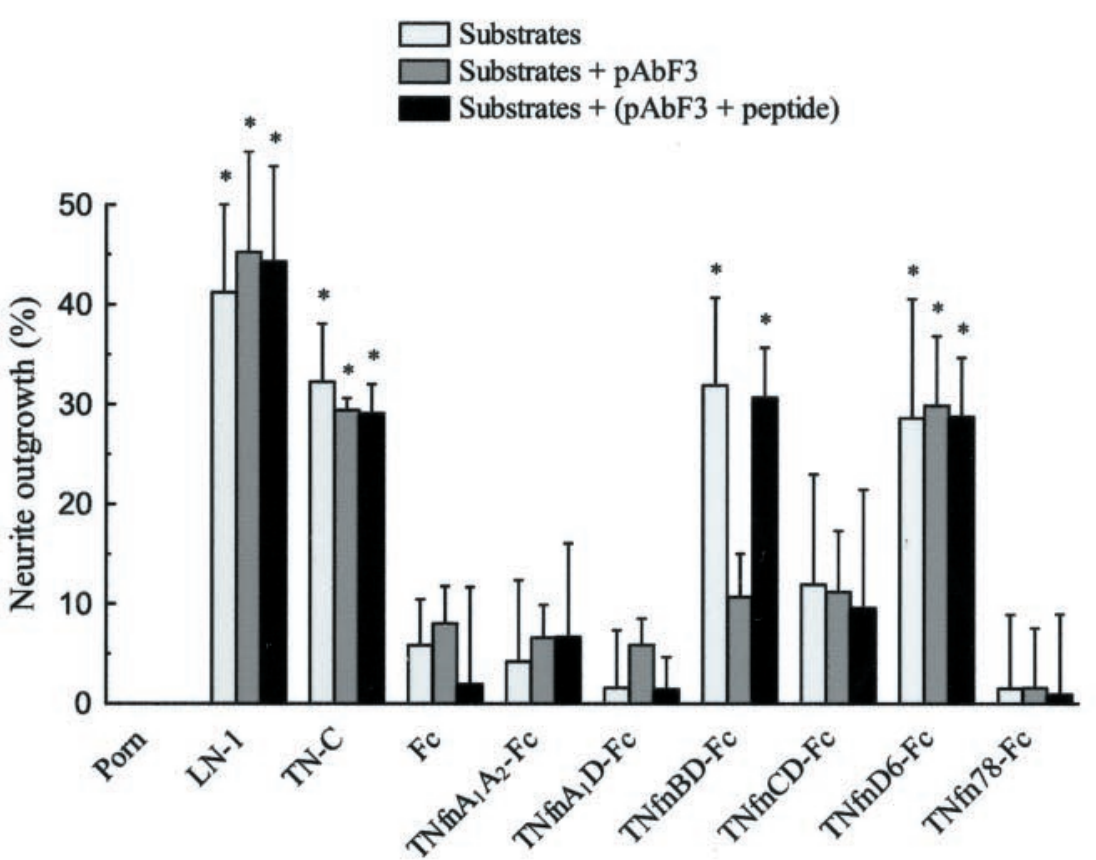

TNfnBD-Fc is specifically mediated by the GPI-anchored IgCAM F3/contactin as its complementary neuronal receptor. The TN-C preparations isolated from whole P7-P14 mouse brains presumably contain a mixture of various different protein isoforms. On the basis of previous RT-PCR analysis of mRNAs, at least 27 different TN-C isoforms are expressed in the postnatal mouse CNS (Joester and Faissner, 1999). The constitutive domains of the smallest variant of TN-C are known not to promote outgrowth of hip- 
TN-C (Kaf 14)

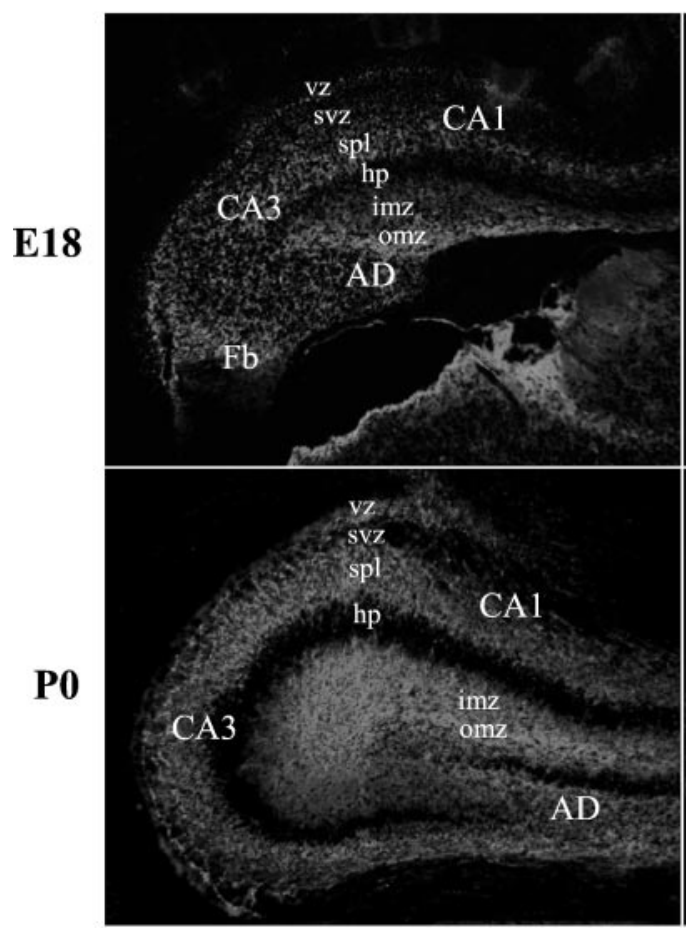

FNIII D (J1/tn2)

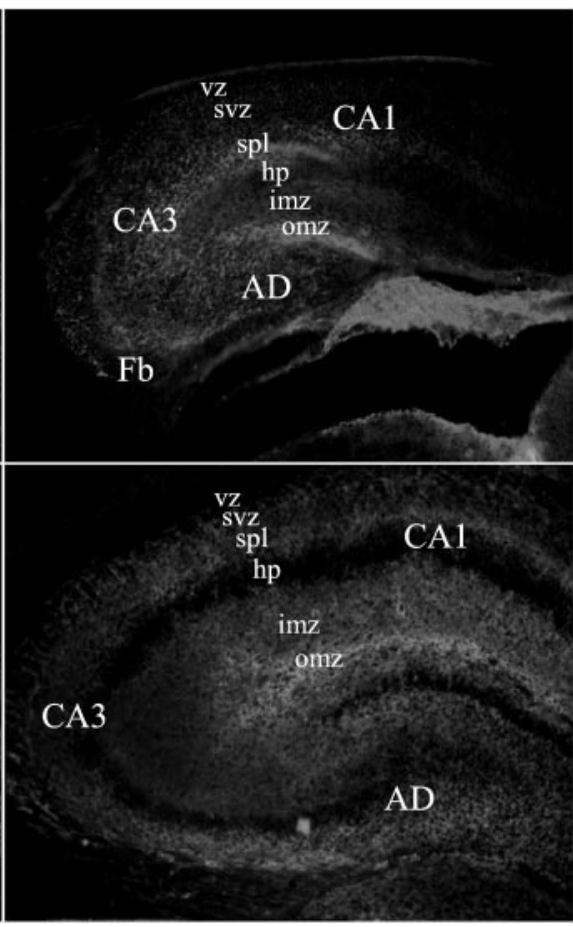

F3/Contactin (pAbF3)

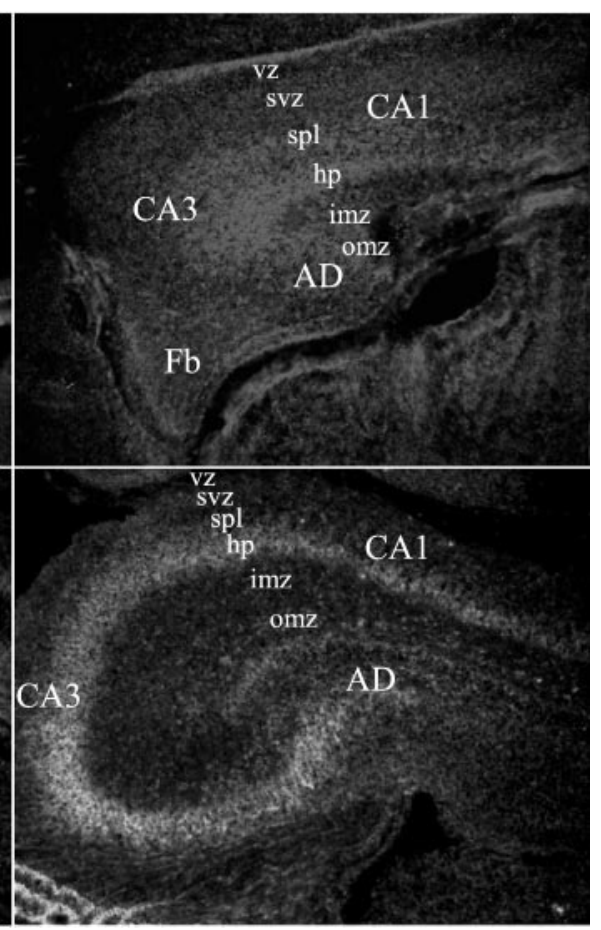

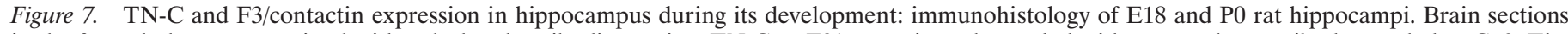

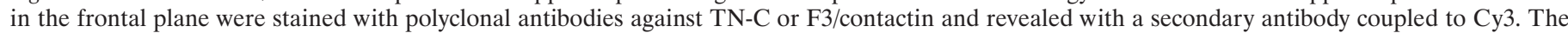

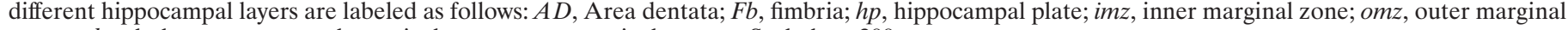
zone; $s p l$, subplate zone; $s v z$, subventricular zone; $v z$, ventricular zone. Scale bar, $200 \mu \mathrm{m}$.

pocampal neurons. Therefore, the observed outgrowth promotion by TN-C preparations in the presence of polyclonal anti-F3 antibodies is probably attributable to the occurrence of isoforms that constitute other alternatively spliced FNIII repeats with neurite growth-promoting properties. In light of the data presented in this study, the pair of FNIII domains D6 constitutes a promising candidate, because TNfnD6-Fc was as efficient a promoter of fiber outgrowth as TNfnBD-Fc, but the effect was not abolished by antibodies to F3/contactin. Along these lines, the chimeric protein TNfnD6-Fc, unlike TNfnBD-Fc, did not react with F3/contactin in the bead aggregation assay or the biochemical pull-down assays performed on CNS extracts. It is noteworthy in this context that the neurite growth-supporting peptide recently reported in domain $\mathrm{D}$ has been proposed to involve a $\beta 1$-type integrin, which could represent a further receptor candidate (Meiners et al., 2001). The individual integrin, however, still remains to be identified.

Interestingly, a previous study has highlighted an interaction of the small isoform of chicken $\mathrm{TN}-\mathrm{C}$ with contactin/F11, the chicken homolog of F3. According to biochemical evidence, the structural basis of this interaction was mapped to the constitutive FNIII 56 repeats (Weber et al., 1996). Although our work cannot exclude the possibility that FNIII 56 modules from mammalian $\mathrm{TN}-\mathrm{C}$ bind to $\mathrm{F} 3 /$ contactin, neurite outgrowth promotion resulting from such an interaction seems less likely. Indeed, an earlier study has demonstrated that the unspliced human TN-C variant moderately induces neurite outgrowth, and this is dependent on FNIII motifs 6-8 and the fibrinogen-like globular domain of the glycoprotein (Meiners and Geller, 1997). However, the possibility that the FNIII 56 cassettes of the small isoform of TN-C might compete with alternatively spliced TN-C motifs for interaction with F3/contactin when the small isoform is present is an inter- esting one, because the small isoform inhibits neurite outgrowth, even in the presence of strong substrate-bound promoters, such as the large TN-C isoform (Lochter et al., 1991, Meiners and Geller, 1997). Hence, there might exist an additional regulatory mechanism based on competition between the short TN-C and the FNIII BD-containing isoforms.

\section{A relevant role for $\mathrm{TN}-\mathrm{C} / \mathrm{F} 3$ interactions during hippocampal development}

During hippocampal development, the migration of neuronal precursors has almost ceased by E18, with the exception of calretinin- and GABA-positive interneurons moving to the dentate gyrus (Linke and Frotscher, 1993; Super and Soriano, 1994). TN-C expression is particularly strong in zones of migration, suggesting a role in related processes. Axonal extension and the establishment of neuronal connections occur from E16 to P5, the majority of projections emerging between E18 and P0 (Super and Soriano, 1994). For example, at E18, Schaffer collaterals penetrate into the inner marginal zone. At E16-E18, afferent entorhinal fibers arborize densely in the outer marginal zone of the subiculum, and at E17, the afferents originating from septohippocampal neurons penetrate different layers, such as the subplate and the inner marginal zone, to connect with the pyramidal neurons. These developmental events unfold in regions corresponding to strongly overlapping expression patterns of $\mathrm{TN}-\mathrm{C}$ and F3/contactin. These observations suggest that the molecules are implicated in the establishment of connections through stimulation of neurite outgrowth. Variations in TN-C transcripts during this period of hippocampal development can be correlated with differential splicing of FNIII BCD domains. At birth, the combination of $\mathrm{BD}$ domains decreases in favor of the combina- 

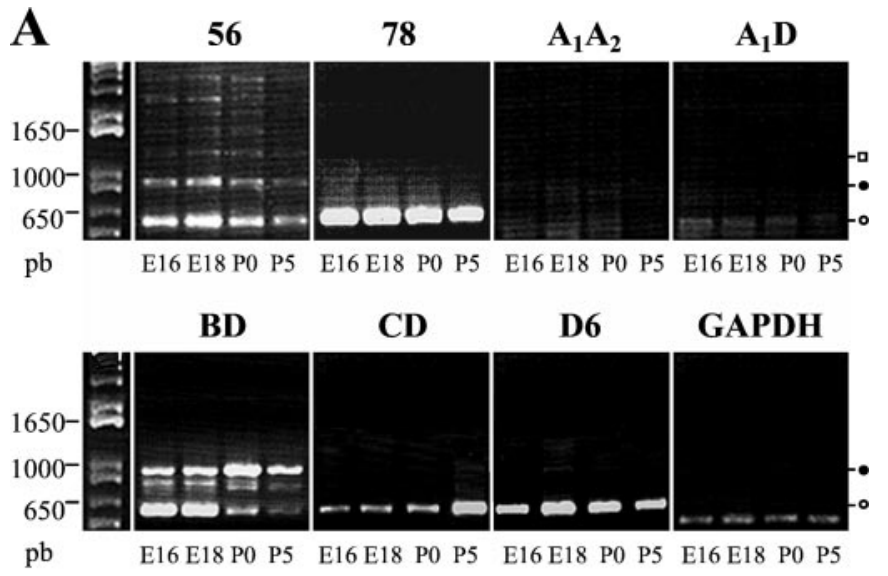

B
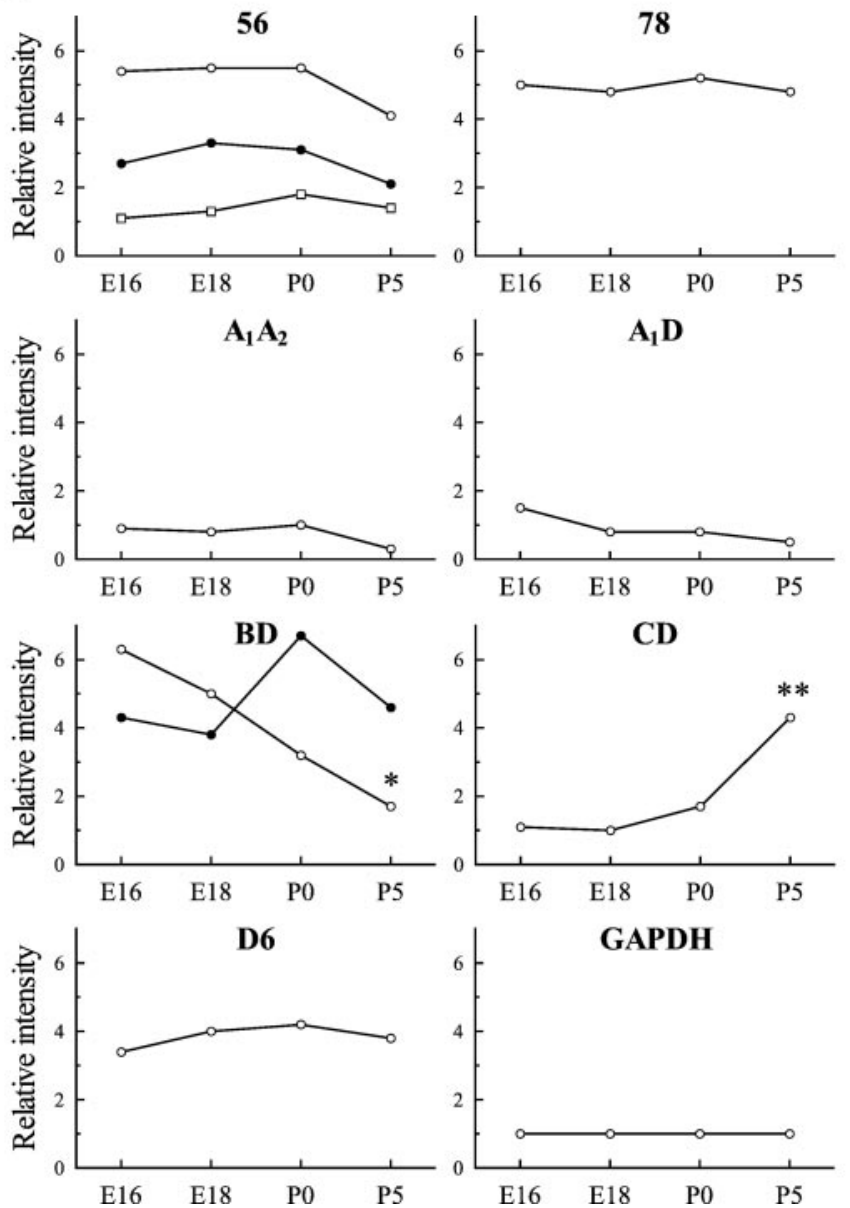

Figure 8. Developmental variation of TN-C isoforms in developing rat hippocampi. $A$, RT-PCR analysis was performed with RNA prepared from E16, E18, P0, and P5 hippocampi, using the primer pairs shown in Table 1 and corresponding to the combinations of FNIII domains tested. $B$, Semiquantitative analysis of isoform transcription. The evaluation of relative isoform prevalences was undertaken by the measurement of band intensity and normalized by comparison with the glyceraldehyde-3-phosphate dehydrogenase $(G A P D H)$ amplification product taken as a measure of relative mRNA concentration. For primers of the FNIII 56 repeats, only small variants with no (open circles), one (filled circles), and two (open squares) spliced FN III domains are represented. For primers of FN III BD modules, two combinations were obtained containing the two spliced FNIII BD domains BD (open circles) or the three BCD motifs ( filled circles). Note the downregulation of the FNIII BD modules $\left(^{*}\right)$ concomitant with an increase of the CD combination (**) during hippocampal maturation. tion $\mathrm{BCD}$, as a result of the insertion of the $\mathrm{C}$ domain. FNIII domain $\mathrm{C}$ has been proposed in a previous study as a regulator of axon guidance (Meiners et al., 1999a). Hence, the influence of TN-C on the development of the hippocampus seems to shift from outgrowth promotion before birth toward favoring axonal guidance during postnatal stages. This process might be paralleled by a relative reduction of the significance of the F3/contactin receptor interaction. In contrast, D6-dependent events, possibly mediated by an independent, as yet unknown $\beta 1$-type integrin (see above), would not be compromised. Thus, the tuning of receptor efficacy by combinatorial FNIII-domain rearrangement could contribute an additional layer of complexity to regulatory processes during neurohistogenesis. The implication of TN-C in hippocampal development, particularly in the establishment of axonal connections, is supported by phenotypic characteristics observed in knock-out mice for TN-C. In fact, animals defective for the $\mathrm{TN}-\mathrm{C}$ gene are viable and fertile and were first described as showing no biological defects. However, knock-out mice for TN-C exhibit numerous abnormalities associated with neurological disorders (Mackie and Tucker, 1999). These behavioral anomalies include hyperactivity, deficiencies in sensorimotor coordination, low interest in environmental exploration, and diminished learning capacities. This last observation indicates that $\mathrm{TN}-\mathrm{C}$, or some isoforms of TN-C, might be associated with the development of the hippocampus, because this anatomical structure is known to be a major region of the brain implicated in short-term memory processes. On the other hand, interestingly, the elimination of the F3/contactin gene results in severe neurological deficits, e.g., impaired cerebellar coordination, which suggests an important role of the glycoprotein in the establishment of axonal pathways (Berglund et al., 1999).

In summary, the present study demonstrates that, in vitro, the TN-C glycoprotein regulates hippocampal neurite outgrowth through its FNIII BD domains and that it does so by interacting with the complementary neuronal receptor F3/contactin. Localization data are consistent with the interpretation that such a mechanism also operates in vivo. However, this outside-in signaling pathway mediated by TN-C does not exclude other cellular response pathways initialized by different receptors, because other parts of the molecule, which are also supportive for fiber outgrowth, do not bind to F3/contactin. Therefore, the control of axonal growth by TN-C constitutes a complex sequence of events modulated by different combinations of FNIII domains, whose localized expression in the developing CNS might specifically define neuronal microenvironments as permissive or inhibitory for process outgrowth, extension, and guidance.

\section{REFERENCES}

Banker GA, Cowan WM (1977) Rat hippocampal neurons in dispersed cell culture. Brain Res 126:397-442.

Bartsch U (1996) The extracellular matrix molecule tenascin-C: expression in vivo and functional characterization in vitro. Prog Neurobiol 49:145-168.

Berglund EO, Murai KK, Fredette B, Sekerkova G, Marturano B, Weber L, Mugnaini E, Ranscht B (1999) Ataxia and abnormal cerebellar microorganization in mice with ablated contactin gene expression. Neuron 24:739-750.

Brümmendorf T, Hubert M, Treubert U, Leuschner R, Tárnok A, Rathgen FG (1993) The axonal recognition molecule F11 is a multifunctional protein: specific domains mediate interactions with $\mathrm{Ng}$-CAM and restrictin. Neuron 10:711-727.

Buttiglione M, Revest JM, Rougon G, Faivre-Sarrailh C (1996) F3 neuronal adhesion molecule controls outgrowth and fasciculation of cerebellar granule cell neurites: a cell-type-specific effect mediated by the Ig-like domains. Mol Cell Neurosci 8:53-69.

Buttiglione M, Revest JM, Pavlou O, Karagogeos D, Furley A, Rougon G, Faivre-Sarrailh C (1998) A functional interaction between the neuro- 
nal adhesion molecules TAG-1 and F3 modulates neurite outgrowth and fasciculation of cerebellar granule cells. J Neurosci 18:6853-6870.

Chen S, Mantei N, Dong L, Schachner M (1999) Prevention of neuronal cell death by neural adhesion molecules L1 and CHL1. J Neurobiol 38:428-439.

Denda S, Reichardt LF, Muller U (1998) Identification of osteopontin as a novel ligand for the integrin alpha8 beta1 and potential roles for this integrin-ligand interaction in kidney morphogenesis. Mol Biol Cell 9:1425-1435

Dörries U, Schachner M (1994) Tenascin mRNA isoforms in the developing mouse brain. J Neurosci Res 37:336-347.

Dörries U, Taylor J, Xiao Z, Lochter A, Montag D, Schachner M (1996) Distinct effects of recombinant tenascin-C domains on neuronal cell adhesion, growth cone guidance, and neuronal polarity. J Neurosci Res 43:420-438.

Faissner A, Kruse J (1990) J1/tenascin is a repulsive substrate for central nervous system neurons. Neuron 5:627-637.

Götz B, Scholze A, Clement A, Joester A, Schütte K, Wigger F, Frank R, Spiess E, Ekblom P, Faissner A (1996) Tenascin-C contains distinct adhesive, anti-adhesive, and neurite outgrowth promoting sites for neurons. J Cell Biol 132:681-699.

Gulcher JR, Nies DE, Marton LS, Stefansson K (1989) An alternatively spliced region of the human hexabrachion contains a repeat of potential N-glycosylation sites. Proc Natl Acad Sci USA 86:1588-1592.

Husmann K, Faissner A, Schachner M (1992) Tenascin promotes cerebellar granule cell migration and neurite outgrowth by different domains in the fibronectin type III repeats. J Cell Biol 116:1475-1486.

Jalkanen M, Elenius K, Salmivirta M (1992) Syndecan-a cell surface proteoglycan that selectively binds extracellular effector molecules. Adv Exp Med Biol 313:79-85.

Joester A, Faissner A (1999) Evidence for combinatorial variability of tenascin-C isoforms and developmental regulation in the mouse central nervous system. J Biol Chem 274:17144-17151.

Joester A, Faissner A (2001) The structure and function of tenascins in the nervous system. Matrix Biol 20:13-22.

Koch T, Brugger T, Bach A, Gennarini G, Trotter J (1997) Expression of the immunoglobulin superfamily cell adhesion molecule F3 by oligodendrocyte-lineage cells. Glia 19:199-212.

Linke R, Frotscher M (1993) Development of the rat septohippocampal projection: tracing with DiI and electron microscopy of identified growth cones. J Comp Neurol 332:69-88.

Lochter A, Vaughan L, Kaplony A, Prochiantz A, Schachner A, Faissner A (1991) J1/tenascin displays dual, opposite effects on neurite outgrowth. J Cell Biol 113:1159-1171.

Mackie EJ, Tucker RP (1999) The tenascin-C knockout revisited. J Cell Sci 112:3847-3853.

Meiners S, Geller HM (1997) Long and short splice variants of human tenascin differentially regulate neurite outgrowth. Mol Cell Neurosci 10:100-116.

Meiners S, Mercado ML, Nur-e-Kamal MS, Geller HM (1999a) Tenascin-C contains domains that independently regulate neurite outgrowth and neurite guidance. J Neurosci 19:8443-8453.
Meiners S, Powell EM, Geller HM (1999b) Neurite outgrowth promotion by the alternatively spliced region of tenascin-C is influenced by cell-type specific binding. Matrix Biol 18:75-87.

Meiners S, Nur-e-Kamal MS, Mercado ML (2001) Identification of a neurite outgrowth-promoting motif within the alternatively spliced region of human tenascin-C. J Neurosci 21:7215-7225.

Milev P, Maurel P, Haring M, Margolis RK, Margolis RU (1996) TAG1/axonin-1 is a high-affinity ligand of neurocan, phosphacan/proteintyrosine phosphatase-zeta/beta, and N-CAM. J Biol Chem 271: 15716-15723.

Milev P, Fischer D, Haring M, Schulthess T, Margolis RK, ChiquetEhrismann R, Margolis RU (1997) The fibrinogen-like globe of tenascin-C mediates its interactions with neurocan and phosphacan/ protein-tyrosine phosphatase-zeta/beta. J Biol Chem 272:15501-15509.

Mueller BK (1999) Growth cone guidance: first steps towards a deeper understanding. Annu Rev Neurosci 22:351-388.

Norenberg U, Hubert M, Brummendorf T, Tarnok A, Rathjen FG (1995) Characterization of functional domains of the tenascin-R (restrictin) polypeptide: cell attachment site, binding with F11, and enhancement of F11-mediated neurite outgrowth by tenascin-R. J Cell Biol 130:473-484.

Rauch U, Clement A, Retzler C, Fröhlich L, Fässler R, Göhring W, Faissner A (1997) Mapping of a defined neurocan binding site to distinct domains of tenascin-C. J Biol Chem 272:26905-26912.

Revest JM, Faivre-Sarrailh C, Maeda N, Noda M, Schachner M, Rougon G (1999) The interaction between F3 immunoglobulin domains and protein tyrosine phosphatases zeta/beta triggers bidirectional signalling between neurons and glial cells. Eur J Neurosci 11:1134-1147.

Saga Y, Tsukamoto T, Jing N, Kusakabe M, Sakakura T (1991) Murine tenascin: cDNA cloning, structure and temporal expression of isoforms. Gene 104:177-185.

Super H, Soriano E (1994) The organization of the embryonic and early postnatal murine hippocampus. II. Development of entorhinal, commissural, and septal connections studied with the lipophilic tracer DiI. J Comp Neurol 344:101-120.

Tessier-Lavigne M, Goodman CS (1996) The molecular biology of axon guidance. Science 274:1123-1133.

Varnum-Finney B, Venstrom K, Muller U, Kypta R, Backus C, Chiquet M, Reichardt LF (1995) The integrin receptor alpha 8 beta 1 mediates interactions of embryonic chick motor and sensory neurons with tenascin-C. Neuron 14:1213-1222.

Weber P, Ferber P, Fischer R, Winterhalter KH, Vaughan L (1996) Binding of contactin/F11 to the fibronectin type III domains 5 and 6 of tenascin is inhibited by heparin. FEBS Lett 389:304-308.

Weller A, Beck S, Ekblom P (1991) Amino acid sequence of mouse tenascin and differential expression of two tenascin isoforms during embryogenesis. J Cell Biol 112:355-362.

Yokosaki Y, Matsuura N, Higashiyama S, Murakami I, Obara M, Yamakido M, Shigeto N, Chen J, Sheppard D (1998) Identification of the ligand binding site for the integrin alpha 9 beta 1 in the third fibronectin type III repeat of tenascin-C. J Biol Chem 273:11423-11428. 